\title{
ROS-dependent phosphorylation of Bax by wortmannin sensitizes melanoma cells for TRAlL-induced apoptosis
}

\author{
S-A Quast ${ }^{1,2}$, A Berger ${ }^{1,3}$ and J Eberle ${ }^{\star, 1}$
}

The pathways of reactive oxygen species (ROS)-mediated apoptosis induction, of Bax activation and the sensitization of tumor cells for TRAIL (TNF-related apoptosis-inducing ligand)-induced apoptosis are still largely elusive. Here, sensitization of melanoma cells for TRAIL by the PI3-kinase inhibitor wortmannin correlated to the activation of mitochondrial apoptosis pathways. Apoptosis was dependent on Bax and abrogated by Bcl-2 overexpression. The synergistic enhancement was explained by Bax activation through wortmannin, which tightly correlated to the characteristic Bax phosphorylation patterns. Thus, wortmannin resulted in early reduction of the Bax-inactivating phosphorylation at serine-184, whereas the Bax-activating phosphorylation at threonine-167 was enhanced. Proving the responsibility of the pathway, comparable effects were obtained with an Akt inhibitor (MK-2206); while suppressed phosphorylation of serine-184 may be attributed to reduced Akt activity itself, the causes of enhanced threonine-167 phosphorylation were addressed here. Characteristically, production of ROS was seen early in response to wortmannin and MK-2206. Providing the link between ROS and Bax, we show that abrogated ROS production by $\alpha$-tocopherol or by NADPH oxidase 4 (NOX4) siRNA suppressed apoptosis and Bax activation. This correlated with reduced Bax phosphorylation at threonine-167. The data unraveled a mechanism by which NOX4-dependent ROS production controls apoptosis via Bax phosphorylation. The pathway may be considered for proapoptotic, anticancer strategies.

Cell Death and Disease (2013) 4, e839; doi:10.1038/cddis.2013.344; published online 10 October 2013

Subject Category: Cancer

Induction of apoptosis is explained by two major signaling pathways. Whereas extrinsic pathways are initiated by death ligands, intrinsic pathways are induced by cellular and DNA damage. On one hand, clustering of death receptors in deathinducing signaling complexes leads to the activation of initiator caspase-8 and -10; on the other hand, mitochondria are employed leading to depolarization of the mitochondrial membrane potential $(\Delta \psi \mathrm{m})$ and release of cytochrome $c$, Smac and AIF. ${ }^{1-3}$ Cytochrome $c$ may induce activation of initiator caspase-9, and the different initiator caspases cleave and activate the executioner caspases (-3, -6 and -7), which irreversibly trigger apoptosis by cleavage of a multitude of death substrates. ${ }^{4}$

Mitochondrial apoptosis pathways are critically controlled by Bcl-2 proteins, enclosing antiapoptotic (e.g. Bcl-2 and Mcl-1), proapoptotic multidomain (e.g. Bax and Bak) and proapoptotic BH3-only proteins (e.g. Puma, Noxa and Bid). ${ }^{5}$ The extrinsic pathway may also be enhanced via the mitochondria, as caspase-8 can process and activate the proapoptotic BH3-only protein Bid leading to truncated Bid (tBid). ${ }^{3}$
Bax plays a decisive role in death ligand-induced apoptosis. ${ }^{6}$ Its activation correlates with its mitochondrial translocation and with the conformational changes at the $\mathrm{N}$-terminus (Bax-NT). ${ }^{7}$ The question how Bax activation is regulated, however, remained largely elusive, and only phosphorylation was discussed. ${ }^{8,9}$ Phosphorylation at serine-184 was suggested as inactivating ${ }^{10,11}$ and phosphorylation at threonine-167 as an activating step. ${ }^{12,13}$ Also, reactive oxygen species (ROS) may contribute to the regulation of apoptosis; however, the relation to the described apoptosis pathways again remained elusive. ROS may be produced by NADPH oxidases. ${ }^{14-16}$

TRAIL (TNF-related apoptosis-inducing ligand) induces apoptosis via death receptors DR4 and DR5. It represents a promising anticancer strategy, due to the selective targeting of cancer cells. ${ }^{17,18}$ However, only limited efficacy was seen in clinical trials, which appeared as being related to inducible TRAIL resistance. ${ }^{19,20}$ Treatment with TRAIL was also discussed for therapy-resistant melanoma, but again inducible resistance was seen. ${ }^{21,22}$

\footnotetext{
${ }^{1}$ Department of Dermatology and Allergy, Skin Cancer Center, University Medical Center Charité, Berlin, Germany; ${ }^{2}$ Institute for Chemistry and Biochemistry, Free University of Berlin, Berlin, Germany and ${ }^{3}$ Institute for Biology, Humboldt-University Berlin, Berlin, Germany

*Corresponding author: J Eberle, Department of Dermatology and Allergy, Skin Cancer Center, University Medical Center Charité, Charitéplatz 1,10117 Berlin, Germany. Tel: + 4930450 518383; Fax: + 4930450 518984; E-mail: juergen.eberle@ charite.de

Keywords: Bax; ROS; wortmannin; TRAIL; melanoma

Abbreviations: AIF, apoptosis-inducing factor; ASK-1, apoptosis signal-regulating kinase 1; CDKs, cell cycle-dependent kinases; $\Delta \psi \mathrm{m}$, mitochondrial membrane potential; ERK 1/2, extracellular signal-regulated protein kinases 1/2; GAPDH, glucose-6-phosphate dehydrogenase; JNK, c-Jun N-terminal kinase; LDH, lactate dehydrogenase; NOX4, NADPH oxidase 4; PI3K, phosphoinositide 3-kinase; PKC, protein kinase C; ROS, reactive oxygen species; Smac, second mitochondrial derived activator of caspases; tBid, truncated Bid; TRAIL, TNF-related apoptosis-inducing ligand; TS, TRAIL-selected; VDAC, voltage-dependent anion channel; XIAP, X-chromosome-linked inhibitor of apoptosis protein

Received 02.4.13; revised 26.7.13; accepted 09.8.13; Edited by A Finazzi-Agró
} 
a

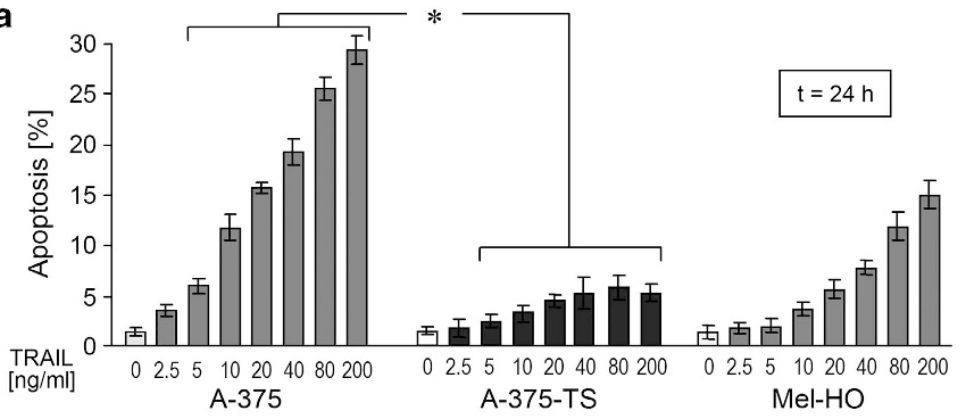

b

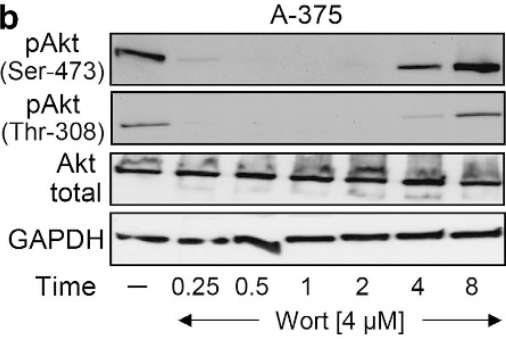

d

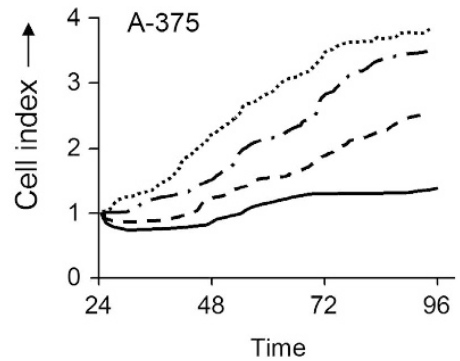

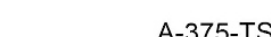
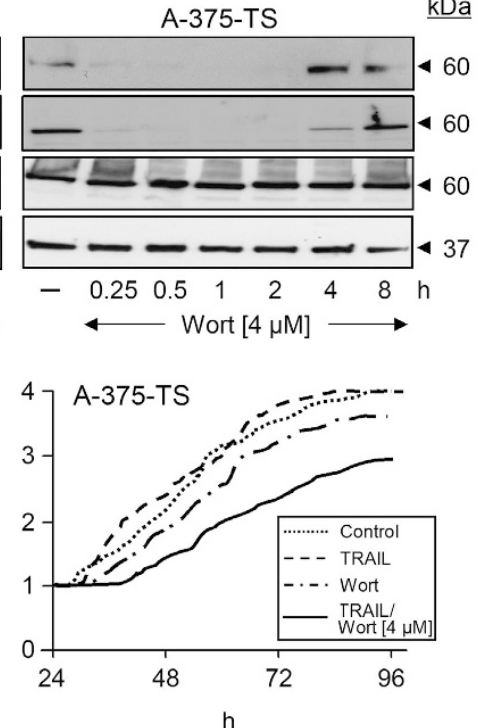
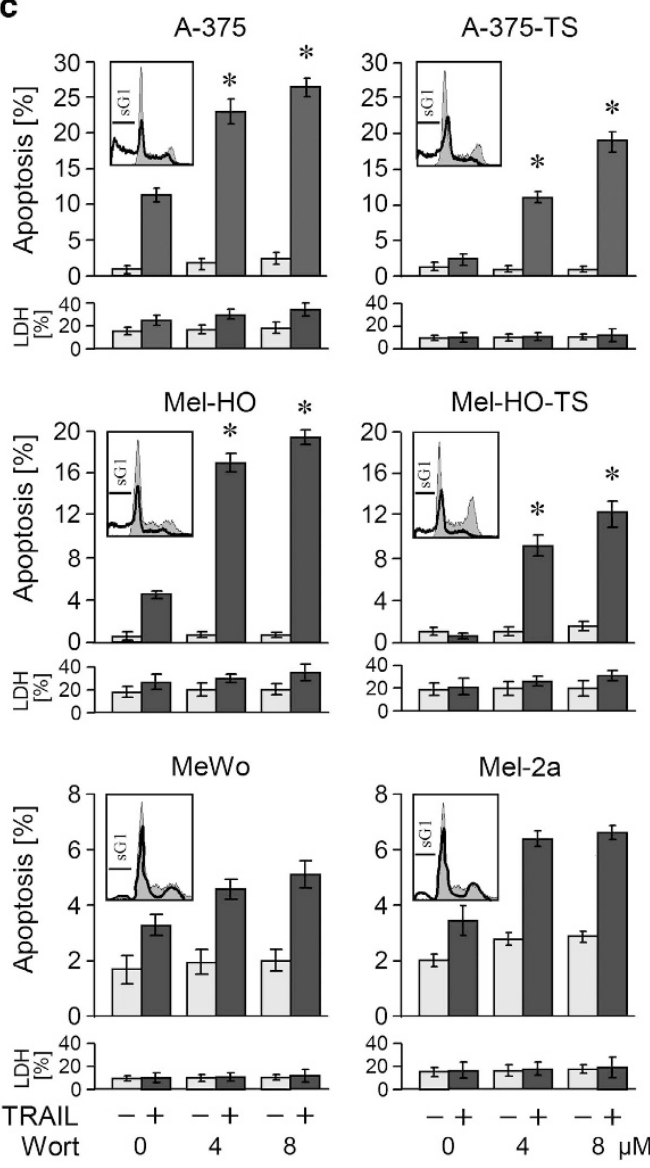

Figure 1 Sensitization of melanoma cells for TRAIL-induced apoptosis by wortmannin. (a) Apoptosis (percentage of sub-G1 cells) was determined by cell cycle analysis in A-375, A-375-TS and Mel-HO cells treated for $24 \mathrm{~h}$ with increasing concentrations of TRAlL $(0-200 \mathrm{ng} / \mathrm{ml})$. Cytotoxicity was determined in parallel by an LDH release assay. Means and SDs are shown of two independent experiments, each one consisting of triplicates. Statistical significance $\left({ }^{*} P<0.005\right)$ is indicated for the comparison of A-375 cells and TRAIL-resistant A-375-TS cells. (b) Time-dependent changes of phosphorylated Akt at serine-473 and at threonine-308 after treatment with $4 \mu \mathrm{M}$ wortmannin are shown by western blotting in A-375 and A-375-TS. The signals of an antibody for total Akt are shown as controls. Equal protein loading ( $30 \mu \mathrm{g}$ per lane) was proven by GAPDH. (c) Apoptosis in response to wortmannin $(4 \mu \mathrm{M}, 8 \mu \mathrm{M})+/$ - TRAlL $(20 \mathrm{ng} / \mathrm{ml})$ was monitored by cell cycle analysis in six melanoma cell lines (A-375, A-375-TS, Mel-HO, Mel-HO-TS, MeWo and Mel-2a). Cytotoxicity was determined in parallel by LDH release (in \%). Statistical significance $\left({ }^{*} P<0.005\right)$ is indicated when comparing TRAIL-treated and wortmannin/TRAIL-treated cells. Insets: Histogram examples of cells treated with wortmannin/TRAIL (open graphs) as compared to DMSO controls (gray). Sub-G1 cell populations are indicated (sG1). (d) Real-time growth curves of A-375 and A-375-TS treated with wortmannin (4 $\mu \mathrm{M})$ and/or TRAlL (20 ng/ml) were compared to DMSO controls. Cell indices were normalized at the time of treatment ( $24 \mathrm{~h}$ after seeding)

Protein kinase inhibitors are attracting increasing attention for cancer therapy since the last few years, and BRAF inhibitors recently led to a breakthrough in melanoma therapy. ${ }^{23}$ Besides MAP kinases, the pathway via phosphoinositide 3-kinases (PI3K) and protein kinase B (Akt) promotes proliferation and survival of tumor cells, ${ }^{24}$ as also reported for melanoma. ${ }^{25,26}$ For targeting PI3K, the fungal metabolite wortmannin has been identified as a specific and covalent inhibitor. ${ }^{27}$ Here, we show enhancement of TRAIL-induced apoptosis by wortmannin, and the underlying mechanisms are also analyzed. Thereby, we describe a new pathway, which provides a link between ROS and Bax activation.

\section{Results}

Enhanced TRAIL-induced apoptosis by wortmannin. For overcoming melanoma resistance to TRAIL-induced apoptosis, the PI3K inhibitor wortmannin was evaluated in
TRAIL-sensitive melanoma cell lines (A-375, Mel-HO), in cell lines that had been selected for TRAIL resistance (A-375-TS, Mel-HO-TS) and in permanent TRAIL-resistant cell lines (MeWo, Mel-2a). TRAIL-selected cells (A-375-TS) revealed resistance even at increased concentrations of TRAIL and did not exceed a plateau of $6 \%$ apoptosis in response to TRAIL (Figure 1a). Wortmannin resulted in immediate downregulation of Akt phosphorylation at serine-473 and threonine-308, as shown in A-375 and A-375-TS at $15 \mathrm{~min}$ of treatment, whereas total Akt levels remained unaffected. This effect lasted for $2 \mathrm{~h}$, after which phosphorylation returned (Figure 1b).

Apoptosis was analyzed by cell cycle analyses, and apoptotic cells were clearly identified as cells with fragmented DNA (sub-G1 cells, Figure 1c, insets). Whereas wortmannin alone (4-8 $\mu \mathrm{M})$ remained largely without effect on apoptosis at $24 \mathrm{~h}$, and TRAIL induced only moderate apoptosis in A-375 $(11 \%)$ and Mel-HO (4\%), significant apoptosis was seen in the 
a
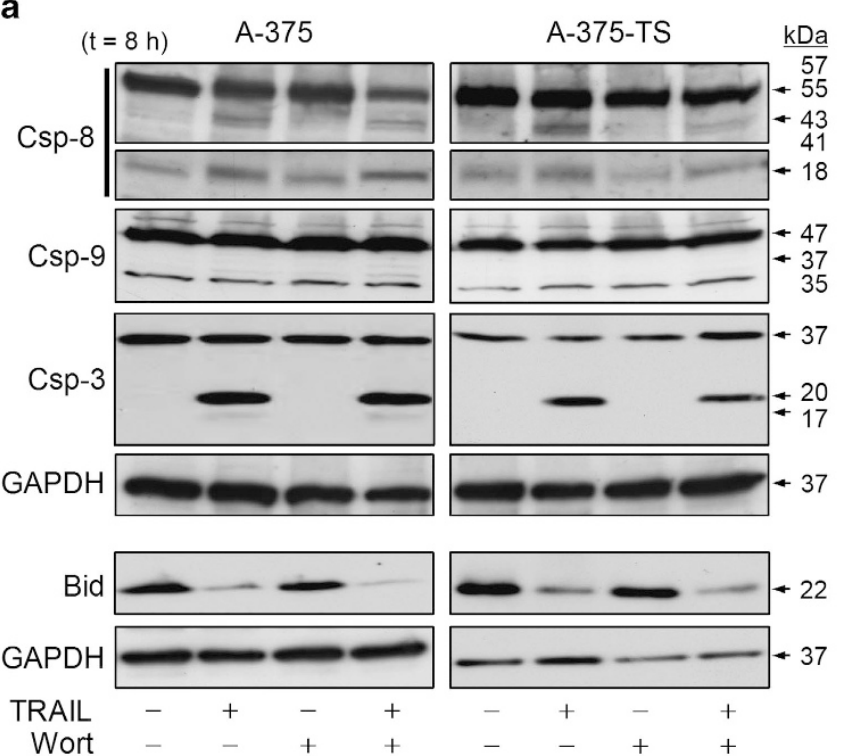

b
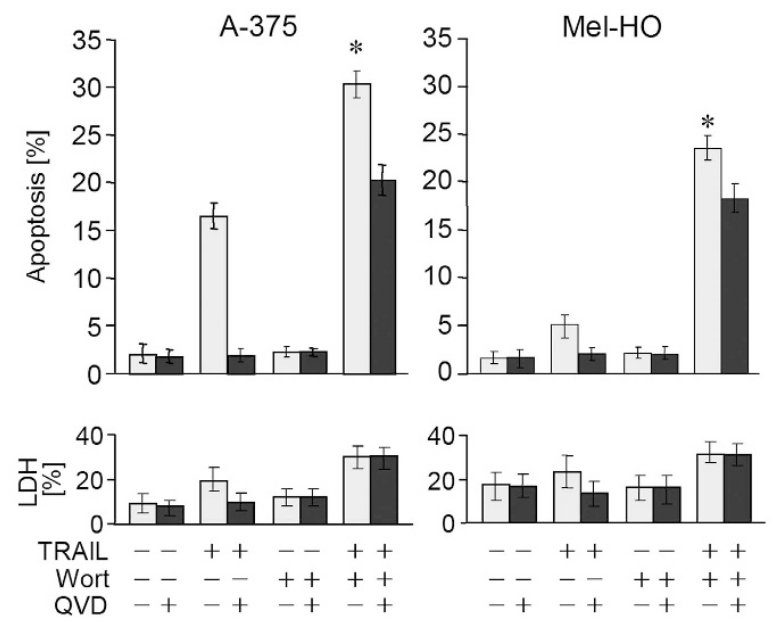

C
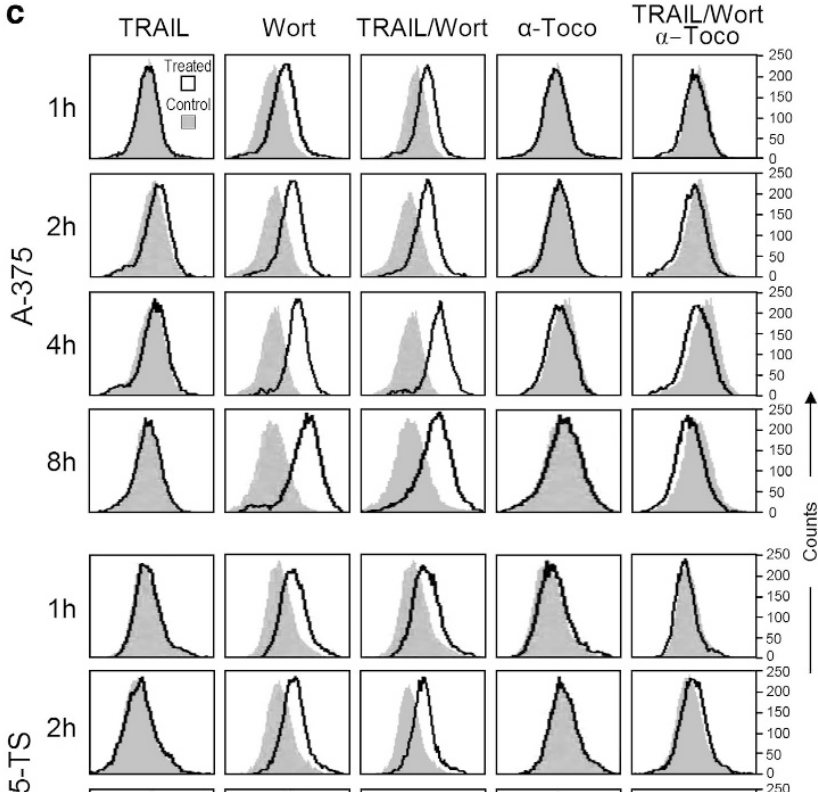

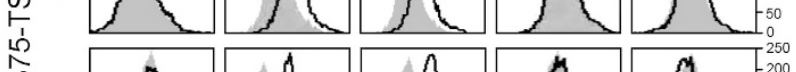
m

$4 \mathrm{~h}$

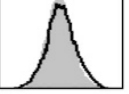

$8 \mathrm{~N}$
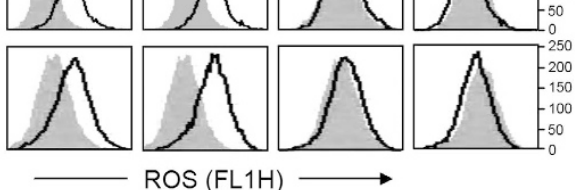

ROS (FL1H)

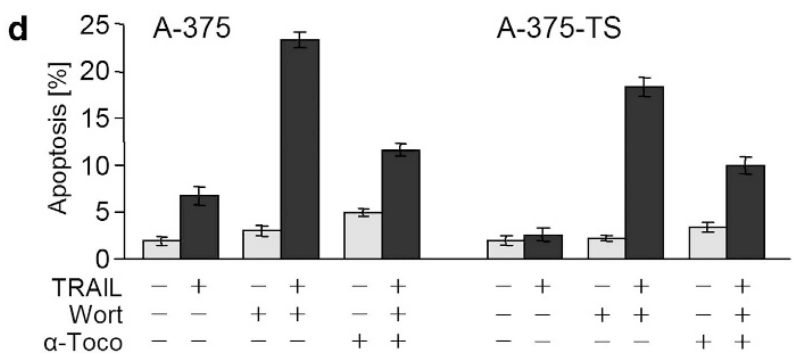

Figure 2 No enhanced caspase processing but ROS production by wortmannin/TRAIL. (a) Processing of caspase-8, $-9,-3$ and cleavage of Bid was monitored by western blotting in A-375 and A-375-TS in response to $8 \mathrm{~h}$ of treatment with wortmannin $(4 \mu \mathrm{M})$ and/or TRAlL $(20 \mathrm{ng} / \mathrm{ml})$. Two independent experiments revealed highly comparable results. (b) Apoptosis (\% of sub-G1 cells) is shown for A- 375 and Mel-HO treated with TRAIL $(20 \mathrm{ng} / \mathrm{ml})$ and/or wortmannin $(4 \mu \mathrm{M})+/$ - the pancaspase inhibitor Q-VD-OPh $\left(10 \mu \mathrm{M}, 1 \mathrm{~h}\right.$ pretreatment). Cytotoxicity was determined in parallel by a LDH release assay (in \%). (c) ROS levels (10 000 cells gated) were determined by $\mathrm{H}_{2} \mathrm{DCFDA}$ staining and flow cytometry in A-375 and A-375-TS at 1, 2, 4 and $8 \mathrm{~h}$ after treatment with $20 \mathrm{ng} / \mathrm{ml}$ TRAlL, $4 \mu \mathrm{M}$ wortmannin and/or $200 \mu \mathrm{M} \alpha$-tocopherol (1 h pretreatment). Treated cells (open graphs) were compared to DMSO controls (gray). Higher fluorescence corresponds to increased ROS levels. (d) Apoptotic rates (\% of sub-G1 cells) were determined in A-375 and A-375-TS in response to TRAIL $(20 \mathrm{ng} / \mathrm{ml})$, wortmannin $(4 \mu \mathrm{M})$ and/or $\alpha$-tocopherol $(200 \mu \mathrm{M}, 1 \mathrm{~h}$ pretreatment)

combinations. Thus, up to $28 \%(\mathrm{~A}-375)$ and $19 \%$ (Mel-HO) apoptosis were obtained in sensitive cells when treated with TRAIL and 4-8 $\mu \mathrm{M}$ wortmannin. In TRAIL-selected A-375-TS and Mel-HO-TS, apoptosis induction was up to $19 \%$ and $13 \%$, respectively. Only the permanent resistant cell lines MeWo and Mel-2a remained largely resistant $(<7 \%)$. At $24 \mathrm{~h}$, cytotoxicity (LDH release) played no role in the responsive cells (Figure 1c). Induced apoptosis by the combinations resulted in a significant decrease of cell proliferation, as determined by real-time cell analysis in A-375 and A-375-TS (Figure 1d).

No caspase activation but enhanced ROS. For understanding the pathways of wortmannin/TRAIL-induced apoptosis, activation of caspases and of Bid was investigated by western blotting at $8 \mathrm{~h}$ of treatment. Despite limited/lacking apoptosis induction in A-375/A-375-TS by TRAIL alone, the initiator caspase-8 was activated, evident by its cleavage products of 43,41 and $18 \mathrm{kDa}$. Also, Bid was processed, evident by the reduction of its proform ( $22 \mathrm{kDa}$ ). However, the main effector caspase-3 appeared as largely arrested at a premature 20-kDa cleavage product; and caspase-9 was not cleaved. Paradoxically, caspase and Bid processing were not enforced by the combination (Figure 2a), despite enhanced apoptosis. In agreement with the caspase-independent pathways, apoptosis by TRAIL/wortmannin was only partially prevented by the pancaspase inhibitor Q-VD-OPh $(10 \mu \mathrm{M})$, as shown in A-375 $(30 \% \rightarrow 20 \%)$ and $\mathrm{Mel}-\mathrm{HO}(22 \% \rightarrow 17 \%)$. 

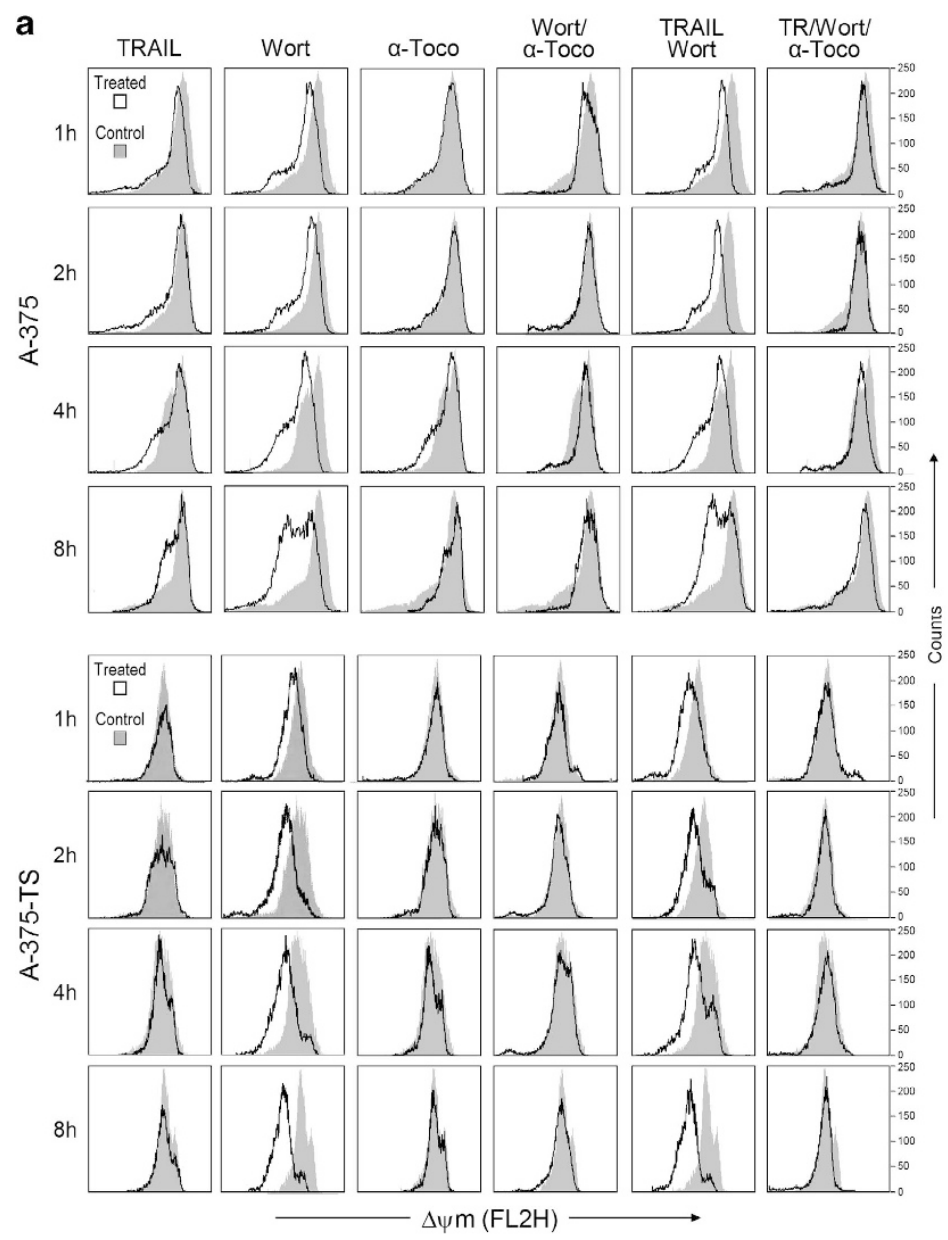
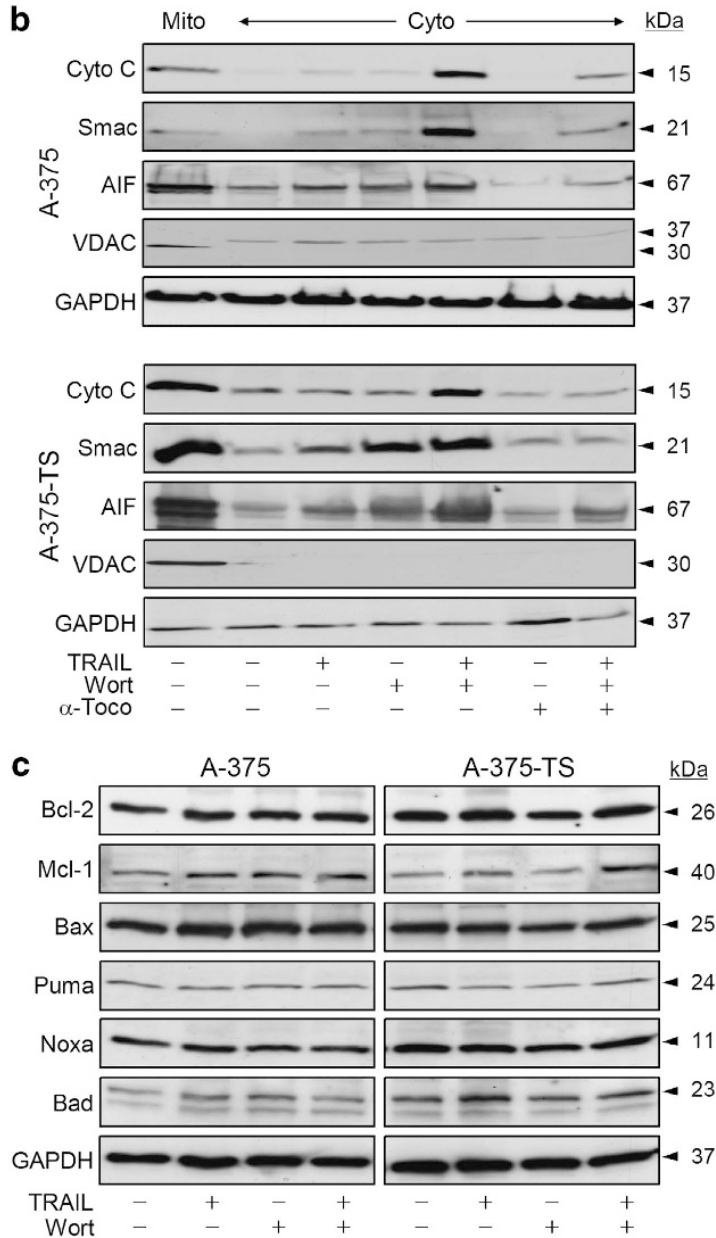

Figure 3 Response of mitochondria and Bcl-2 proteins. (a) Decreased mitochondrial $\Delta / \mathrm{m}$ was determined by flow cytometry after TMRM ${ }^{+}$staining in A-375 and A-375-TS. Cells were treated for $1-8 \mathrm{~h}$ with TRAIL $(20 \mathrm{ng} / \mathrm{ml})$, wortmannin $(4 \mu \mathrm{M})$ and/or $\alpha$-tocopherol $(200 \mu \mathrm{M}, 1 \mathrm{~h}$ pretreatment). Treated cells (open graphs) were compared to DMSO controls (gray). Three independent experiments (each with triplicate values) revealed comparable results. (b) Cytosolic extracts (Cyto) of A-375 and A-375-TS, treated for $2 \mathrm{~h}$ with wortmannin, TRAIL and/or $\alpha$-tocopherol, were analyzed by western blotting for the release of cytochrome $c$, Smac and AIF. Equal protein amounts were loaded as proven by incubation with GAPDH. A mitochondrial extract (Mito) served as control. A western blot for VDAC ( $30 \mathrm{kDa})$ ruled out contaminations of cytosolic extracts with mitochondria. A protein band of $37 \mathrm{kDa}$ seen for A-375 traces back to a previous incubation of the blot with GAPDH (c) Expression of Bcl-2 proteins was determined by western blotting in A-375 and A-375-TS in response to wortmannin $(4 \mu \mathrm{M})$ and/or TRAIL. Some slight differences seen for some proteins were not reproducible in the second, independent experiment (data not shown)

In contrast, apoptosis induced by TRAIL alone was completely blocked (Figure 2b). Thus, mechanisms were suggestive that induced apoptosis caspase-independently.

Caspase-independent apoptosis in melanoma cells can result from enhanced levels of ROS, as we have previously shown. ${ }^{15}$ Indeed, ROS levels were significantly increased in A-375 and A-375-TS by wortmannin alone at $1 \mathrm{~h}$, which further increased with time. In contrast, TRAIL alone had no significant effect on ROS (Figure 2c). The critical role of ROS in apoptosis induction by wortmannin/TRAIL became evident by the ROS scavenger $\alpha$-tocopherol (vitamine E). Pretreatment for $1 \mathrm{~h}$ with $\alpha$-tocopherol prevented ROS production by wortmannin (Figure 2c) and reduced wortmannin/ TRAIL-induced apoptosis by about 50\% (Figure 2d).

Activation of mitochondrial proapoptotic pathways. In parallel with ROS, activation of proapoptotic mitochondrial pathways was seen. Thus, the $\Delta \psi \mathrm{m}$ was decreased by wortmannin alone and in combination at early times (1 h), suggesting loss of $\Delta \psi \mathrm{m}$ as a regulatory step and not as a result of induced apoptosis. TRAIL alone resulted in a slight decrease of $\Delta \psi \mathrm{m}$ only in A-375 but not in A-375-TS, and TRAIL did not enhance the effect of wortmannin on $\Delta \psi \mathrm{m}$. Loss of $\Delta \psi \mathrm{m}$ by wortmannin was abrogated by $\alpha$-tocopherol, thus proving a tight relation between ROS and the mitochondrial response (Figure 3a).

Combination treatments resulted in the release of cytochrome $c$, Smac and apoptosis-inducing factor (AIF), as determined at $2 \mathrm{~h}$, which was also strongly diminished by $\alpha$-tocopherol (Figure 3b). This early mitochondrial activation cannot be explained by changes in the expression of Bcl-2 proteins. Even at later times $(24 \mathrm{~h})$, no significant changes were seen in the expression of antiapoptotic proteins $\mathrm{Bcl}-2, \mathrm{Mcl}-1$ or proapoptotic proteins Bax, Noxa, Puma and Bad (Figure 3c), thus demanding other levels of regulation. 
a
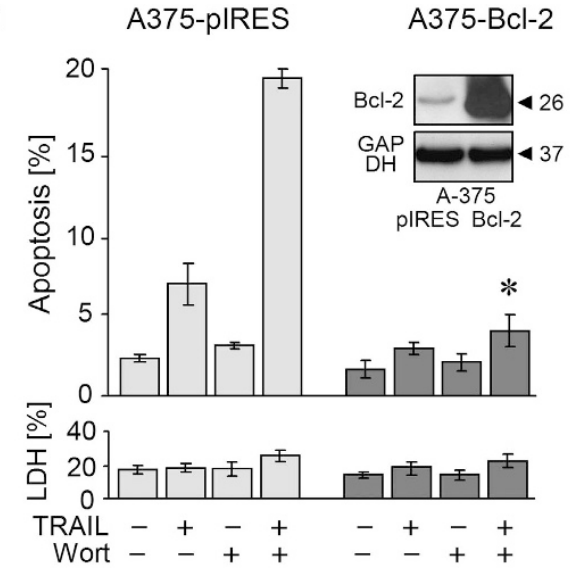

C

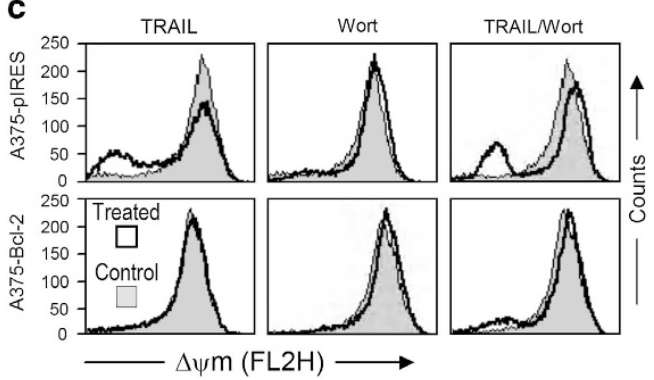

b

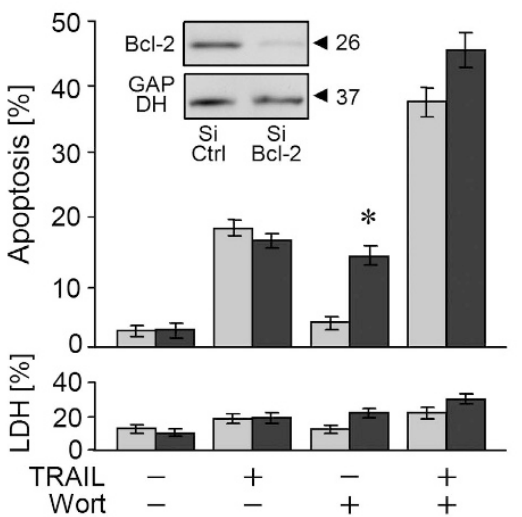

$\mathrm{Mel}-\mathrm{HO}$
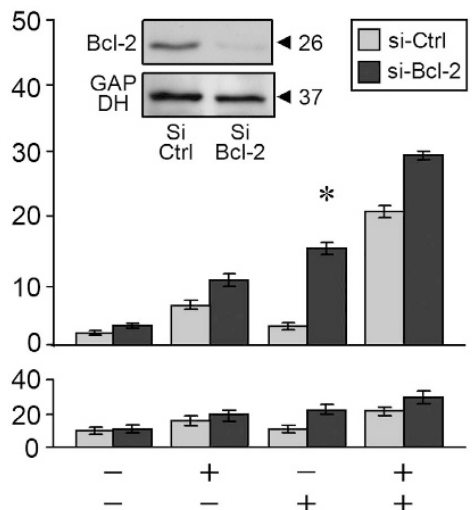

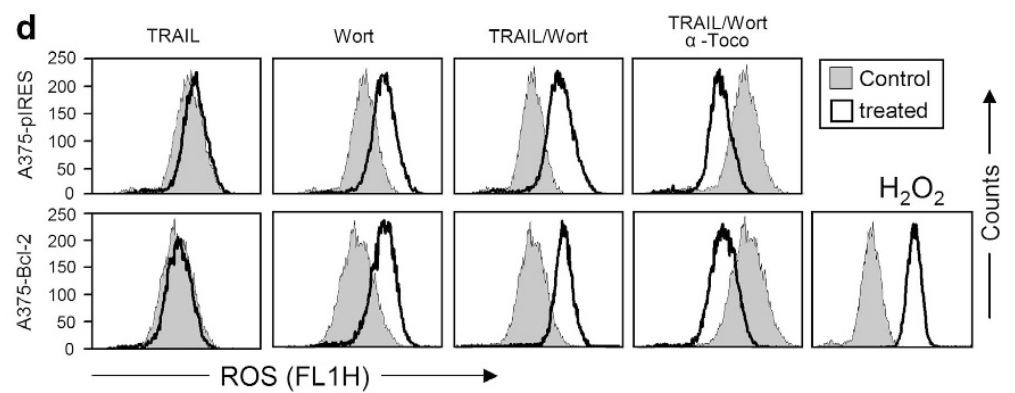

Figure 4 Abrogation of wortmannin/TRAIL-induced apoptosis by exogeneous Bcl-2. (a) Apoptosis by wortmannin/TRAIL was investigated in A-375 cells stably transfected with Bcl-2 (A-375-Bcl-2) and mock-transfected controls (A-375-pIRES). Inset, Bcl-2 expression in both cell clones. (b) Sensitivity for TRAIL/wortmannin-induced apoptosis $(20 \mathrm{ng} / \mathrm{ml} ; 4 \mu \mathrm{M})$ was investigated in A-375 and Mel-HO after siRNA-mediated Bcl-2 knockdown. SiRNA treatment was compared to a siRNA mock control (Si-Ctrl). Apoptosis (\% of sub-G1 cells) and cytotoxicity (\% LDH release) are shown for $24 \mathrm{~h}$ treatment (mean values and SDs of two independent experiments, each with triplicates). Statistical significance is indicated for the response to wortmannin of si-Bcl-2-treated cells as compared to mock controls $\left({ }^{\star} P<0.005\right)$. Insets: Knockdown of Bcl-2 is shown by western blotting. Equal protein loading ( $30 \mu \mathrm{g}$ per lane) was proven by GAPDH. (c) $\Delta \psi \mathrm{m}$ in response to wortmannin $(4 \mu \mathrm{M})$ and TRAlL $(20 \mathrm{ng} / \mathrm{ml})$ treatment $(24 \mathrm{~h})$ is shown for the mock (A-375-pIRES) and the Bcl-2-overexpressing clone (A-375-Bcl-2). Treated cells (open graphs) were compared to DMSO controls (gray). (d) ROS levels were determined by $\mathrm{H}_{2}$ DCFDA staining and flow cytometry in A-375-Bcl-2 and A-375-pIRES at $24 \mathrm{~h}$ of treatment with $20 \mathrm{ng} / \mathrm{ml}$ TRAIL, $4 \mu \mathrm{M}$ wortmannin and/or $\alpha$-tocopherol $(200 \mu \mathrm{M}, 1 \mathrm{~h}$ pretreatment). Treated cells (open graphs) were compared to DMSO controls (gray). $\mathrm{H}_{2} \mathrm{O}_{2}$-treated cells $(200 \mathrm{mM}, 1 \mathrm{~h})$ served as a positive control. Three independent experiments revealed comparable results

Decisive roles of $\mathrm{Bcl}-2$ and Bax. Despite no change at the expression level, decisive roles were assigned to $\mathrm{Bcl}-2$ and Bax. Thus, wortmannin/TRAIL-induced apoptosis was completely prevented by $\mathrm{Bcl}-2$ overexpression in the stably transfected A-375 cells (A-375-Bcl-2), whereas the mock-transfected cells (A-375-pIRES) were sensitive (Figure 4a). Knockdown of Bcl-2 by siRNA, interestingly, enhanced apoptosis induction by wortmannin alone in A-375 and Mel-HO (15\%, 17\%). However, apoptosis by TRAIL/wortmannin was only slightly enhanced (A-375: $38 \% \rightarrow 46 \%$; Mel-HO: $21 \% \rightarrow 29 \%$ ), which may be attributed to the enhanced direct effects of wortmannin. Cytotoxicity (LDH release) remained unaffected (Figure 4b). These data suggested that overexpressed $\mathrm{Bcl}-2$ abrogated the contribution of TRAIL in the combination. On the other hand, Bcl-2 downregulation was redundant to the TRAIL effect, as $\mathrm{Bcl}-2$ could also be blocked by TRAIL-induced Bid activation.

Also, loss of $\Delta \psi \mathrm{m}$ in response to wortmannin/TRAIL was abrogated by $\mathrm{Bcl}-2$ overexpression (Figure 4c). However, ROS production in response to wortmannin remained unaffected from Bcl-2 and was similarly blocked by $\alpha$-tocopherol in both A-375-pIRES and A-375-Bcl-2 (Figure 4d). Thus, ROS production appeared to be independent of the mitochondrial response.
The roles of Bax and Bak were distinguished in a HCT-116 cell culture model that consisted of $\mathrm{Bax}^{+} \mathrm{Bak}^{+}$parental, Bax knockout, Bak knockdown and double knockdown cells. TRAIL/wortmannin significantly induced apoptosis at $24 \mathrm{~h}$ in parental and Bak knockdown cells, demonstrating that Bak played no role in this setting. In clear contrast, Bax knockout completely abrogated TRAIL- and TRAIL/wortmannininduced apoptosis (Figure 5a). Also, in A-375 and Mel-HO melanoma cells, Bax knockdown by siRNA abrogated TRAILand TRAIL/wortmannin-induced apoptosis. Again, cytotoxicity played no role (Figure $5 b$ ).

Further following the pathway, loss of $\Delta \psi \mathrm{m}$ in response to wortmannin or TRAIL/wortmannin was also seen in HCT-116 parental and Bak knockdown cells, whereas Bax knockout and Bax/Bak double knockdown abolished the effects on $\Delta \psi \mathrm{m}$ (Figure 5c). In contrast, ROS production was independent of Bax/Bak expression (Figure $5 d$ ), thus suggesting ROS as initial and upstream of mitochondria.

The essential role of Bax for the mitochondrial response was further investigated by Bax siRNA. Thus, loss of $\Delta \psi \mathrm{m}$ in response to wortmannin and wortmannin/TRAIL was strongly diminished (A-375) or blocked (A-375-TS, Mel-HO) when cells were transfected with Bax siRNA. In contrast, control 
RNA-transfected cells revealed a regular loss of $\Delta \psi \mathrm{m}$ at $2 \mathrm{~h}$ of treatment (Figure 5e).

The critical role of Bax became more evident by its activation. Thus, increased Bax mitochondrial translocation was seen in A-375 and in A-375-TS already at $2 \mathrm{~h}$ (Figure 5f). The time dependency was investigated by the Bax-NT antibody, which selectively binds to the activated Bax with accessible N-terminus. ${ }^{28}$ Significant Bax activation appeared already at $2 \mathrm{~h}$ in A-375 and A-375-TS. Of note, activated Bax was not a result of induced apoptosis, but was seen earlier and in response to wortmannin treatment alone (Figure $5 \mathrm{~g}$ ). Bax activation by wortmannin was prevented by $\mathrm{Bcl}-2$ overexpression (A-375-Bcl-2; Figure 5h), proving Bax suppression by $\mathrm{Bcl}-2$ in wortmannin/TRAIL-induced apoptosis. a

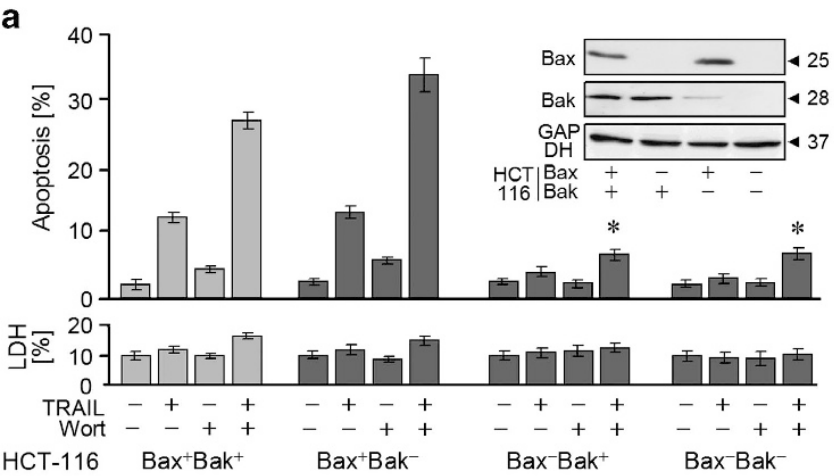

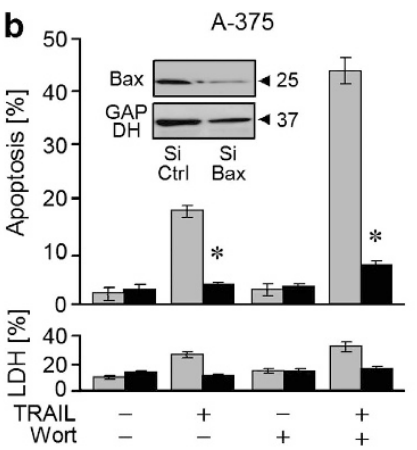

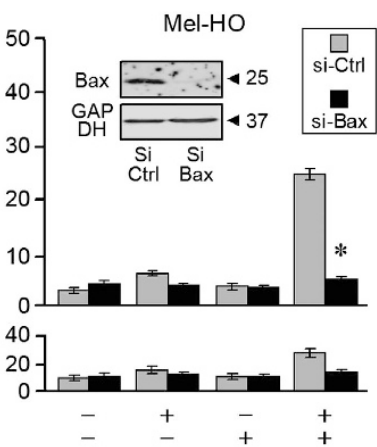

C

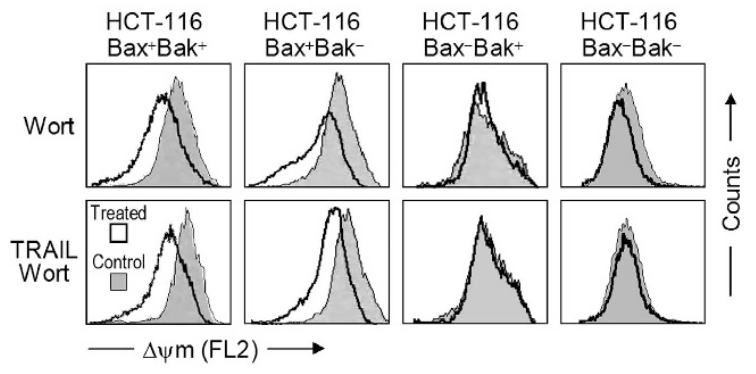

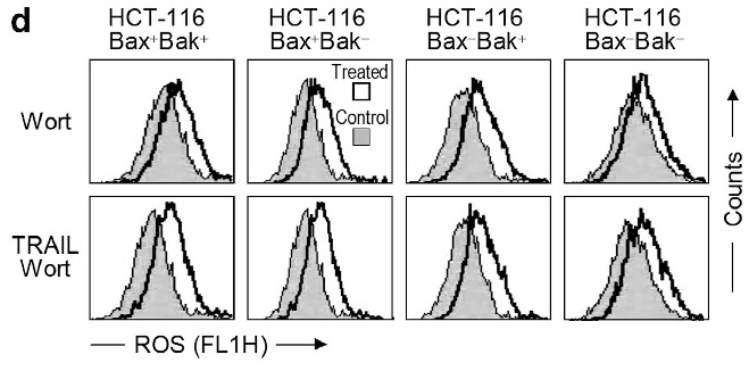

e
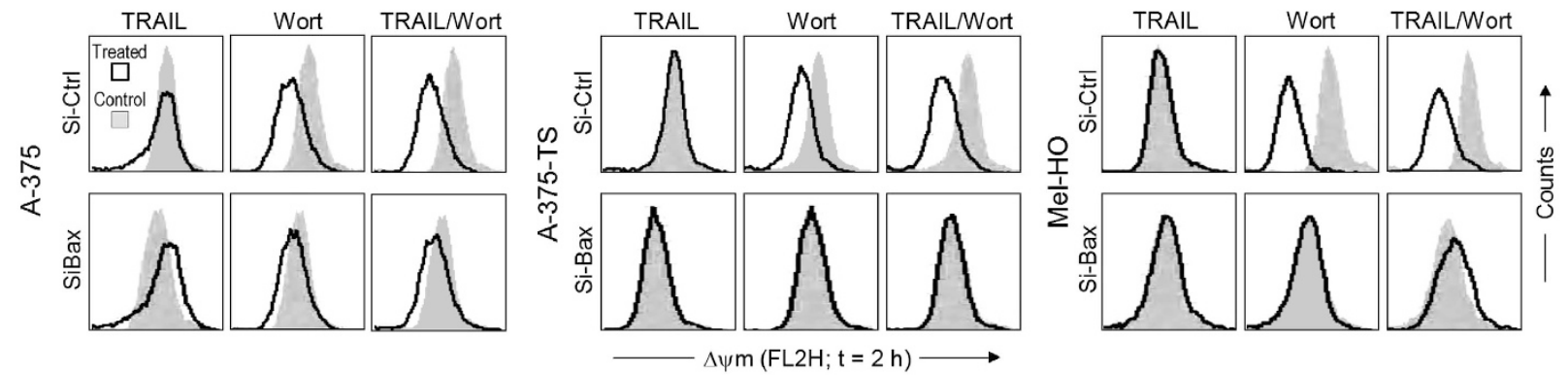

f

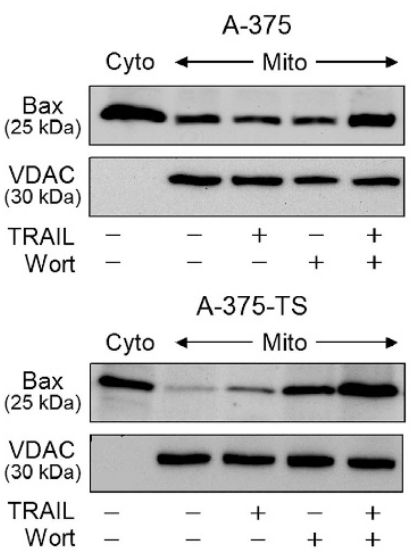

g
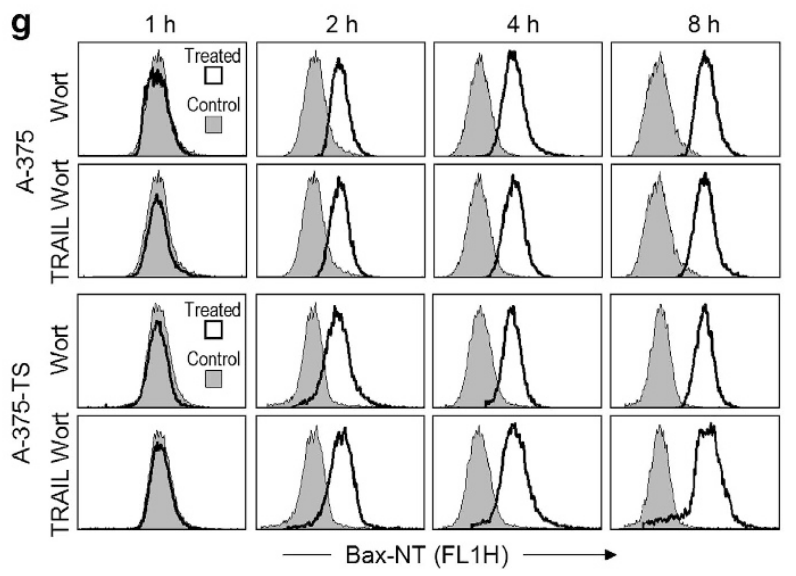

h

A375-pIRES A375-Bcl-2
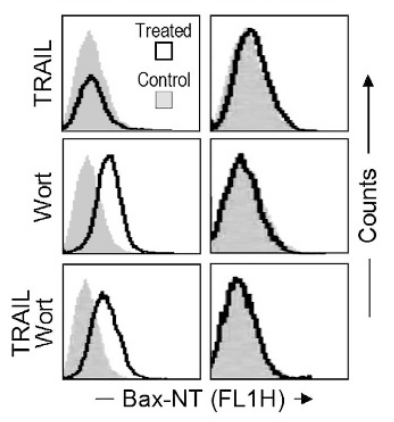
Bax activation by wortmannin through altered phosphorylation. Addressing the relation between kinase inhibition and Bax activation, assays were applied for monitoring Bax phosphorylation at serine-184 and threonine-167. Assays were based on cell permeabilization, staining with phosphorylation-specific antibodies and flow cytometry. Bax phosphorylation at serine-184 had been described as an inactivating step, while phosphorylation at threonine- 167 was described as an activating step. ${ }^{12}$ Reliability of the used antibodies was checked in the HCT-116 Bax knockout cells. Whereas Bax antibodies resulted in significant signals in the HCT-116 parental cells, Bax knockout cells revealed no staining, thus excluding non-specific binding (Figure 6a).

At the time, when wortmannin resulted in Bax activation (Bax-NT, $2 \mathrm{~h}$ ), it also revealed characteristic changes in Bax phosphorylation. Thus, phosphorylation at the deactivating serine-184 site was decreased, while phosphorylation at the activating threonine-167 site was enhanced. In contrast, treatment with TRAIL revealed no effect on Bax phosphorylation (Figure $6 \mathrm{~b}$ and $\mathrm{c}$ ). These data suggested that wortmannin reprogrammed melanoma cells for enhanced apoptosis sensitivity, although it did not trigger apoptosis by itself. The switch appeared to be altered Bax phosphorylation.

Unraveling the role of ROS in this setting, cells were treated with $\alpha$-tocopherol. The antioxidant itself remained without effect on Bax phosphorylation, but reduced the enhanced threonine167 phosphorylation in response to wortmannin (Figure 6c). In contrast, reduced phosphorylation at serine-184 remained unaffected by $\alpha$-tocopherol (Figure 6b), thus distinguishing the regulation of the two Bax phosphorylation sites. Only threonine167 appeared as dependent on ROS. Reduced threonine-167 phosphorylation correlated with reduced Bax activation, as seen by the Bax-NT antibody staining (Figure 6d), while no changes were seen in the Bax total protein level (Figure 6e).

Parallel effects of an Akt inhibitor on apoptosis and Bax. For addressing the relation of PI3K and Akt inhibition in this setting, some experiments were repeated with the allosteric Akt inhibitor MK-2206. It resulted in a concentration-dependent and long-lasting $(24 \mathrm{~h})$ downregulation of $\mathrm{Akt}$ phosphorylation, as shown for serine-473 in A-375, A-375-TS and Mel-HO (Figure 7a). Comparable to wortmannin, MK-2206 resulted in a significant and dose-dependent enhancement of TRAIL-induced apoptosis in TRAIL-sensitive and in resistant melanoma cells, as determined at $24 \mathrm{~h}$ by cell cycle analyses (A-375, 48\%; Mel-HO, 24\%; A-375-TS, 28\%). Again, cytotoxicity played no role (Figure $7 \mathrm{~b}$ ). In parallel to wortmannin, ROS levels were significantly enhanced by MK-2206, as shown in A-375 and Mel-HO at $2 \mathrm{~h}$ of treatment, and ROS production was interrupted by $\alpha$-tocopherol (Figure 7c).

Also, MK-2206 resulted in characteristic changes in Bax phosphorylation, as decreased serine-184 and enhanced threonine-167 phosphorylation, seen in A-375, A-375-TS and $\mathrm{Mel}-\mathrm{HO}$ at $2 \mathrm{~h}$ of treatment. Furthermore, changes correlated with an enhanced Bax activation (Bax-NT; Figure 7d).

NOX4 is essential for wortmannin-induced ROS production. For unraveling the ROS pathway in this setting, the function of NADPH oxidase 4 (NOX4) was investigated. Downregulation of NOX4 by siRNA significantly reduced apoptosis by wortmannin/TRAIL, as shown in A-375 $(44 \% \rightarrow$ $19 \%)$ and Mel-HO $(28 \% \rightarrow 11 \%)$. In contrast, TRAIL-induced apoptosis in A-375 was not affected by NOX4 siRNA (Figure 8a). Proving the critical role of NOX4 for wortmannininduced ROS, NOX4 siRNA completely suppressed ROS production in A-375 and Mel-HO (Figure $8 \mathrm{~b}$ ).

Highly comparable to the effects of $\alpha$-tocopherol on Bax phosphorylation and Bax activation, displayed in Figure 6, also downregulation of NOX4 by siRNA completely abrogated the enhanced phosphorylation at threonine-167, but remained without effect on serine-184, as shown in A-375, A-375-TS and $\mathrm{Mel}-\mathrm{HO}$ at $2 \mathrm{~h}$ of treatment. Abrogation of wortmanninmediated Bax phosphorylation at threonine-167 by NOX4 knockdown also suppressed Bax activation (Bax-NT, Figure 8c). These data suggest a NOX4-dependent pathway leading from PI3K inhibition to Bax activation (Figure 8d).

\section{Discussion}

Based on the above data, a new pathway is suggested that depends on ROS-mediated Bax activation, and explains the sensitization of melanoma cells for TRAIL by wortmannin. As shown here as well as in previous work, TRAIL itself results in caspase-8 and Bid activation in both sensitive and resistant cells. ${ }^{29,30}$ Activated Bid can antagonize $\mathrm{Bcl}-2$, and may thus overcome the Bcl-2-mediated antiapoptotic barrier in melanoma cells. However, a second antiapoptotic barrier is based

Figure 5 Role of Bax. (a) Apoptosis by wortmannin/TRAIL was investigated in HCT-116 parental cells $\left(\mathrm{Bax}^{+}, \mathrm{Bak}^{+}\right.$) and in subclones with knockdown for Bax and/or Bak. Statistical significance of reduced apoptosis in treated subclones is indicated $\left({ }^{*} P<0.005\right)$. Expression of Bax and Bak in the respective cell clones is shown in the inset. (b) Apoptosis (\% of sub-G1 cells) and cytotoxicity (\% LDH release) are shown after siRNA-mediated Bax knockdown (24 h) in A-375 and Mel-HO treated for $24 \mathrm{~h}$ with TRAIL $(20 \mathrm{ng} / \mathrm{ml})+1-$ wortmannin $(4 \mu \mathrm{M})$. The respective mock control (Si-Ctrl) is shown for comparison (Mean values and SDs of two independent experiments, each one with triplicates). Statistical significance is indicated $\left({ }^{*} P<0.005\right)$, when comparing si-Bax and si-Ctrl-transfected cells. Knockdown of Bax is shown by western blotting in insets. Equal protein loading (30 $\mu \mathrm{g}$ per lane) was proven by GAPDH. (c) The mitochondrial $\Delta \psi \mathrm{m}$ was determined in indicated cell clones treated with wortmannin $(4 \mu \mathrm{M})$ or wortmannin/TRAIL for $2 \mathrm{~h}$. Treated cells (open graphs) were compared to DMSO controls (gray). (d) ROS levels were determined in HCT-116 parental cells and in subclones with knockdown for Bax and/or Bak treated with wortmannin $(4 \mu \mathrm{M})$ or wortmannin/TRAIL for $2 \mathrm{~h}$. In each case, three independent experiments with triplicates showed highly comparable results. (e) The mitochondrial membrane potential $(\Delta \psi \mathrm{m})$ was determined in A-375, A-375-TS and Mel-HO treated with TRAlL (20 ng/ml) and/or wortmannin $(4 \mu \mathrm{M})$ for $2 \mathrm{~h}$. Treated cells (open graphs) were compared to DMSO controls (gray). Before, cells were transfected with Bax siRNA (Si-Bax) or the respective control RNA (Si-Ctrl). (f) Mitochondrial extracts (Mito) of A-375 and A-375-TS treated for $2 \mathrm{~h}$ with TRAIL $+/$ - wortmannin $(4 \mu \mathrm{M})$ were analyzed for Bax translocation by western blotting. Equal loading was proven by the mitochondrial protein VDAC; a cytosolic extract is shown for control (Cyto). (g) A-375 and A-375-TS cells were treated for 1-8h with wortmannin $(4 \mu \mathrm{M})$ or with wortmannin/TRAIL followed by flow cytometry analysis for Bax conformational changes (Bax-NT antibody; two independent experiments with triplicates). (h) A-375-pIRES and A-375-Bcl-2 cells were treated for $2 \mathrm{~h}$ with wortmannin $(4 \mu \mathrm{M})+/$ - TRAIL (20 ng/ml) followed by flow cytometry analysis for Bax conformational changes (Bax-NT antibody; two independent experiments with triplicates) 
a Bax total pBax(Ser-184) pBax(Thr-167)
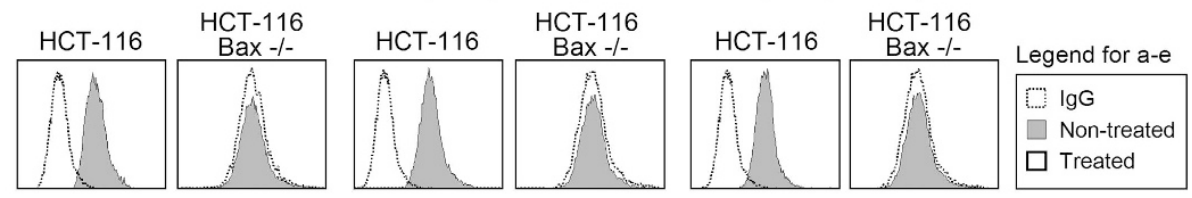

b

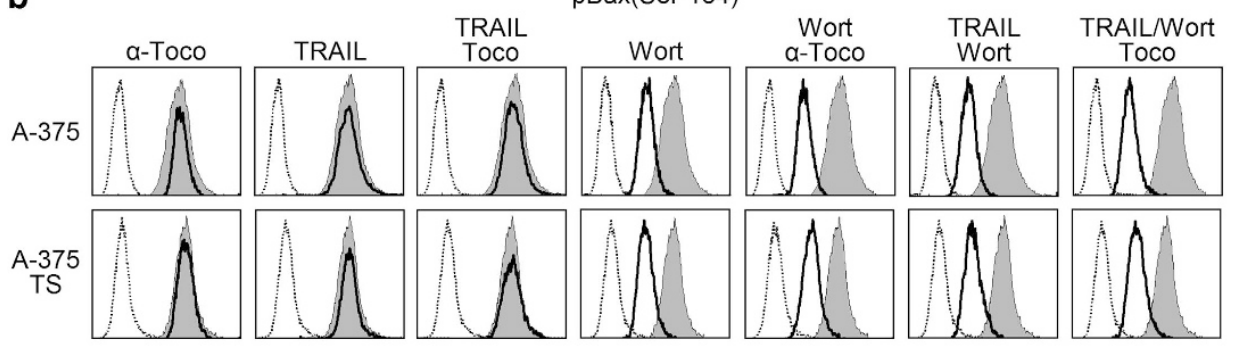

C

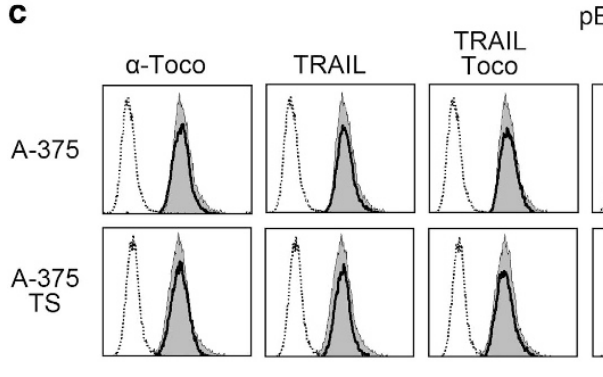

pBax(Thr-167)
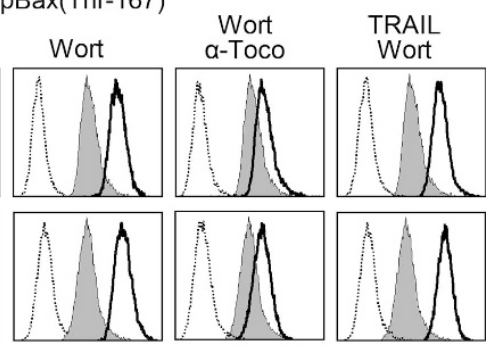

TRAIL/Wort

d
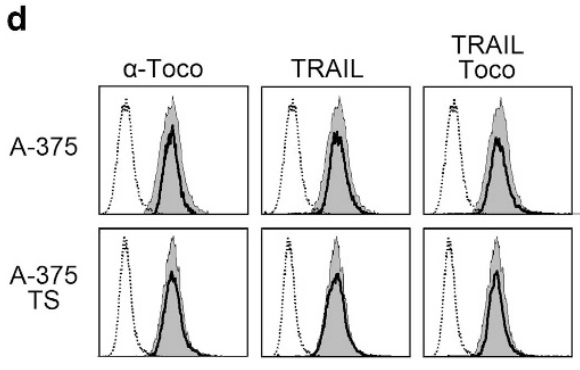

Bax NT
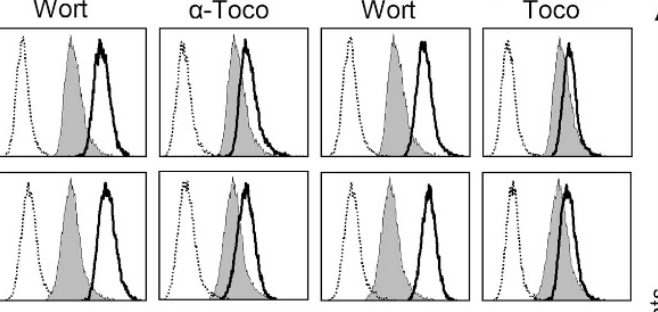

e
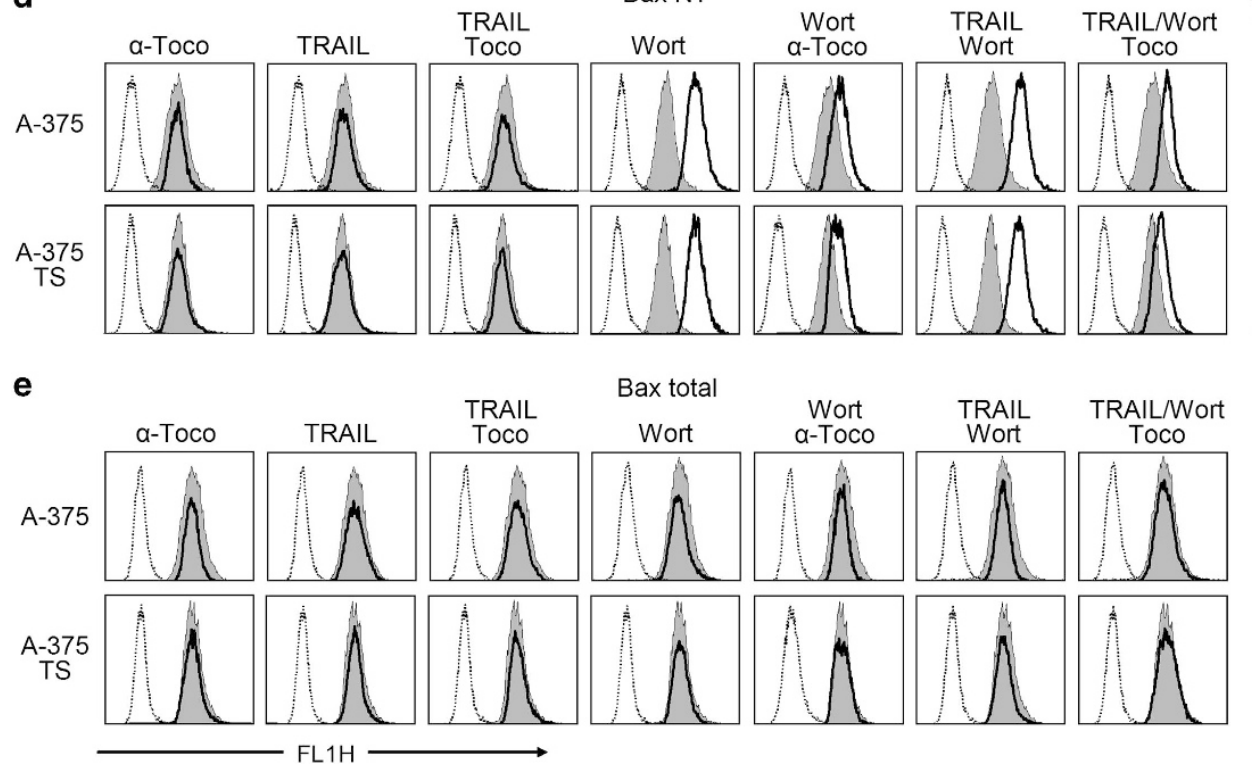

Figure 6 Changes at the level of Bax phosphorylation and relation to ROS. (a) Flow cytometry signals for Bax were compared in HCT-116 parental cells (Bax ${ }^{+}$) and in HCT-116 Bax knockout cells (Bax ${ }^{-1}$ ). Antibodies for total Bax were used, as well as those for Bax phosphorylated at serine-184 and at threonine-167, respectively. Non-treated cells (gray) are shown in overlays with IgG1-stained controls (open graphs). Two independent experiments with triplicates revealed identical results. (b-e) A-375 and A-375-TS were treated for $2 \mathrm{~h}$ with wortmannin $(4 \mu \mathrm{M})$, TRAIL $(20 \mathrm{ng} / \mathrm{ml})$ and/or $\alpha$-tocopherol (200 $\mu \mathrm{M}, 1 \mathrm{~h}$ pretreatment). The drugs were applied together at and for the same time. For subsequent flow cytometry, cells were stained with antibodies specific for (b) pBax(Ser-184), (c) pBax(Thr-167), (d) activated Bax (Bax-NT) and (e) for total Bax as control. Treated cells (open graphs) are shown in overlays with DMSO controls (gray) and IgG1-stained controls (dashed line). Two complete and independent experiments with triplicates revealed comparable results

on the inactive Bax. This second barrier could be overcome by the PI3K inhibitor wortmannin, as demonstrated here (Figure 8d).
The inhibitory effect of wortmannin on PI3K has been well described in previous studies resulting in suppression of the Akt prosurvival pathway. ${ }^{27,31}$ Furthermore, a role of Akt in 
a

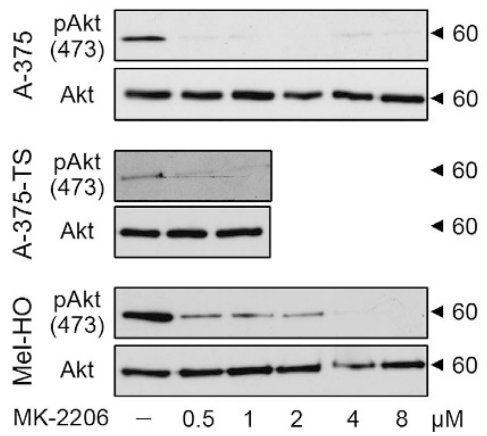

b

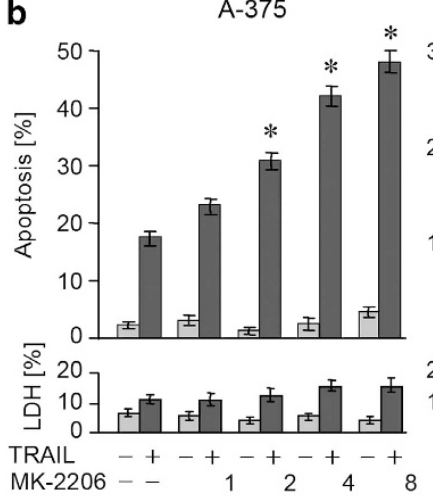

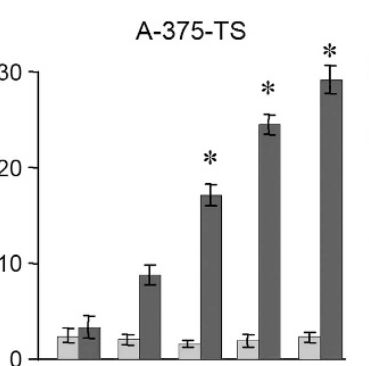

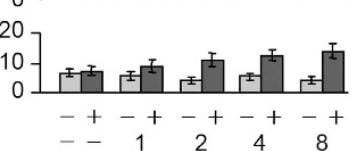

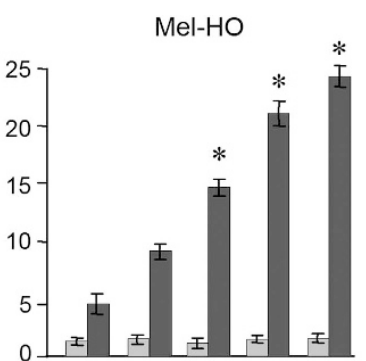

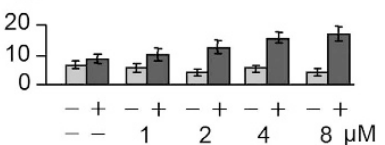

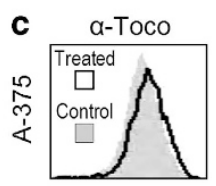
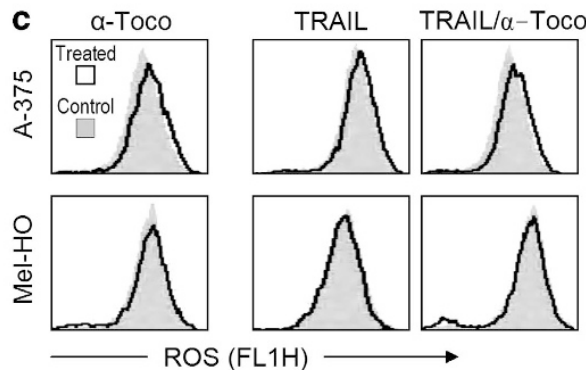

A-375

d

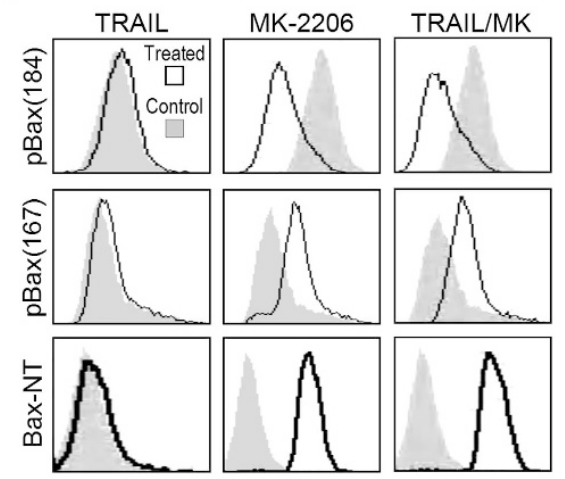

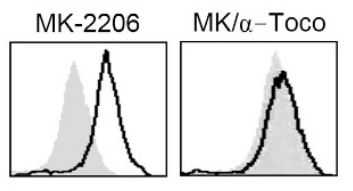
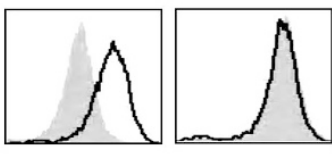

A-375-TS
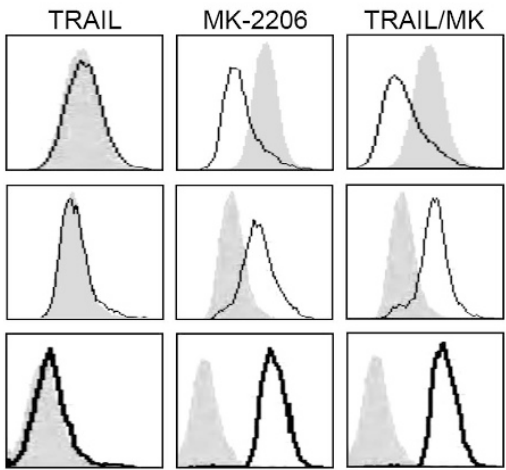
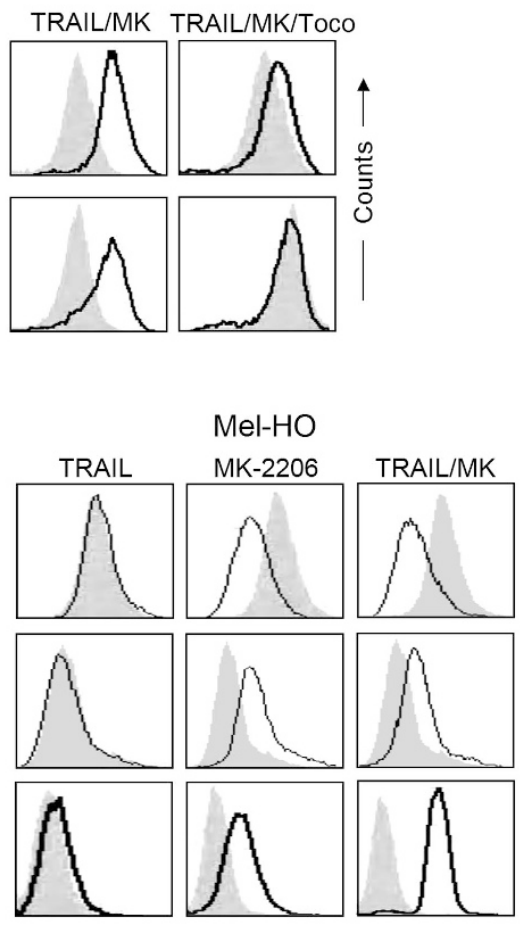

Figure 7 Enhanced TRAlL-induced apoptosis and Bax activation by the Akt inhibitor MK-2206. (a) A-375, A-375-TS and Mel-HO cells were treated with increasing concentrations of the allosteric Akt inhibitor MK-2206 (0.5-8 $\mu \mathrm{M})$, and the effects on Akt phosphorylation (serine-473) were monitored by western blotting after $24 \mathrm{~h}$. Signals of an antibody for total Akt (Akt) served as controls. (b) Apoptosis (percentage of sub-G1 cells) and cytotoxicity (LDH release) were determined in these cells after $24 \mathrm{~h}$ of treatment (means and SDs of two independent experiments, each one with triplicates). Statistical significance $\left({ }^{\star} P<0.005\right)$ is indicated, when comparing treatments with MK-2206/TRAIL and TRAIL alone. (c) ROS levels were determined by $\mathrm{H}_{2}$ DCFDA staining and flow cytometry in A-375 and Mel-HO at $2 \mathrm{~h}$ after starting treatment with $20 \mathrm{ng} / \mathrm{ml}$ TRAIL, $4 \mu \mathrm{M}$ MK-2206 and/or $\alpha$-tocopherol (200 $\mu \mathrm{M}$, $1 \mathrm{~h}$ pretreatment). Treated cells (open graphs) were compared to DMSO controls (gray). Two independent experiments (each with triplicates) revealed comparable results. (d) Flow cytometry signals for Bax phosphorylation (Ser-184; Thr-167) and Bax activation (Bax-NT) were compared in A-375, A-375-TS and Mel-HO cells after $2 \mathrm{~h}$ treatment with TRAlL $(20 \mathrm{ng} / \mathrm{ml}), \mathrm{MK}-2206(4 \mu \mathrm{M})$ and MK-2206/TRAlL. Treated cells (open graphs) are shown in overlays with DMSO controls (gray). Two complete and independent experiments with triplicates revealed the same results

TRAIL resistance has already been suggested in different tumor cell models, ${ }^{32,33}$ including melanoma cells. ${ }^{34}$ As phosphorylation of Akt at serine-473 and threonine-308 represents a characteristic activity of $\mathrm{PI} 3 \mathrm{~K},{ }^{35}$ the here-seen downregulation of both phosphorylation sites in response to wortmannin clearly proved its specific inhibitory effect in melanoma cells. The role of the Akt pathway in the effects of wortmannin was furthermore proven by the allosteric Akt inhibitor MK-2206, ${ }^{36,37}$ which produced largely parallel effects to wortmannin in melanoma cells.
As concerns apoptosis regulation, phosphorylation of Bax at serine-184 by Akt has been reported, which was further related to an inhibition of Bax activity. ${ }^{10,11}$ Indeed, by applying a new phosphorylation assay, significant decrease of Bax phosphorylation at serine-184 is demonstrated here in response to wortmannin. But this de-phosphorylation obviously reflected only one half of the pathways supporting Bax activation. Thus, multiple pathways have been described downstream of $\mathrm{Akt}^{24}$ which also include the regulation of two NADPH oxidases (NOX1, NOX4). 
Thus, enhanced NOX activity was reported in response to Akt inhibition in pancreatic carcinoma and in chronic myeloid leukemia cells. ${ }^{38,39}$
NOX enzymes may produce large amounts of superoxide, and are thus tightly related to cellular ROS pathways. ${ }^{40}$ Supporting the role of ROS-dependent pathways, we found a

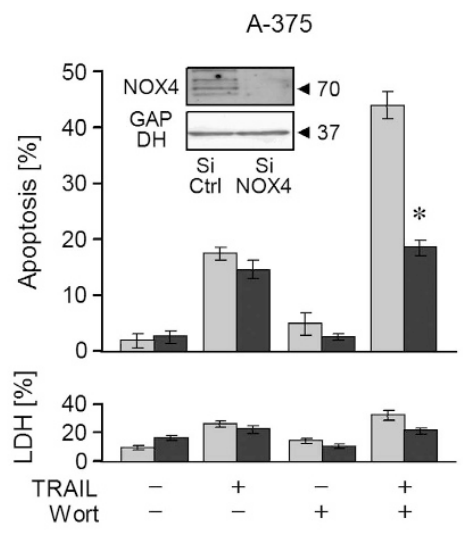

b

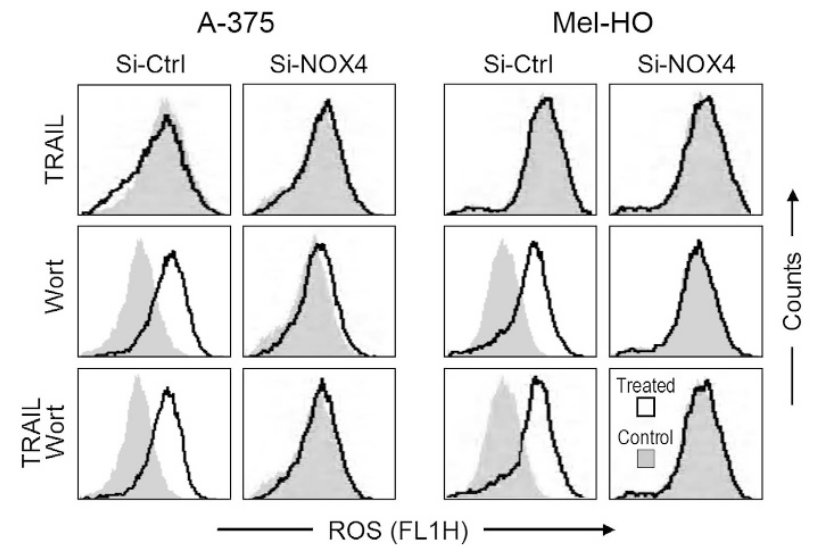

d
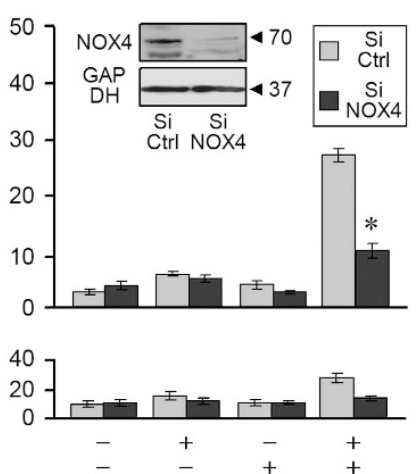

Mel-HO

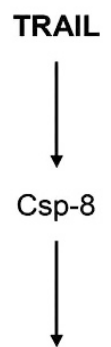

tBid

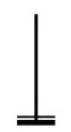

Bcl-2

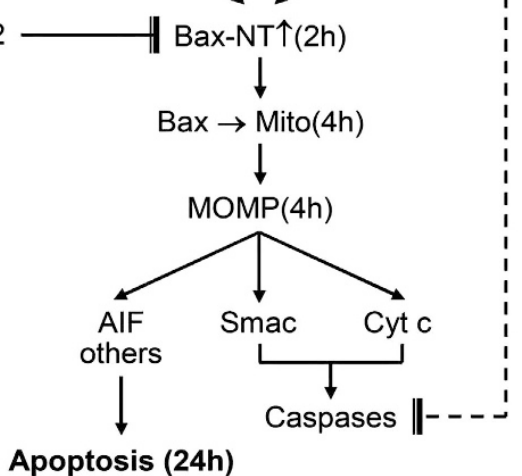

c
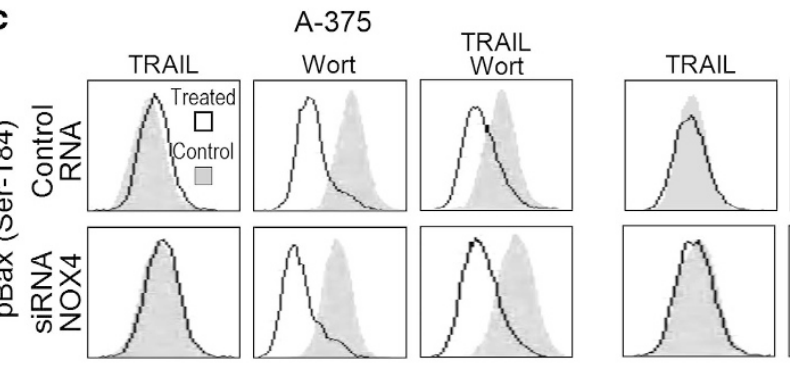

A-375-
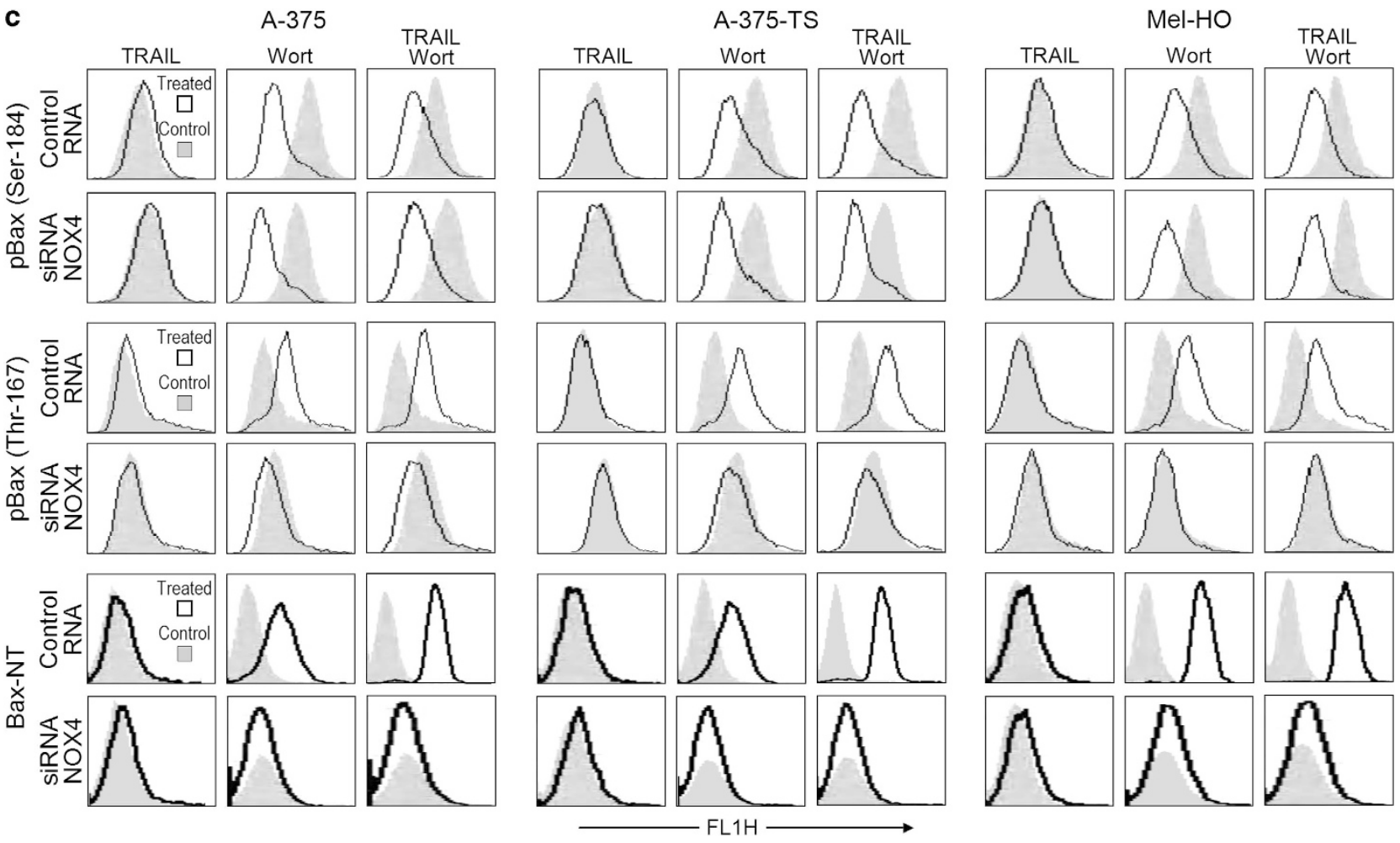
significantly increased ROS levels in melanoma cells in response to wortmannin treatment. Of note, ROS production appeared as an early step already at $1 \mathrm{~h}$, which it was also seen in response to wortmannin alone and clearly distinguishes this effect from secondary effects in course of induced apoptosis. The significance of ROS for efficient induction of apoptosis in melanoma cells has already been reported in a previous study. ${ }^{15}$ Its significance in wortmannin/TRAIL-induced apoptosis was proven here by the ROS scavenger $\alpha$-tocopherol. The effect could be further narrowed down to the activity of NOX4, as its siRNA-mediated downregulation prevented wortmannin/ TRAIL-mediated ROS production as well as induced apoptosis.

The way in which ROS could contribute to apoptosis became apparent by analyzing the Bax phosphorylation sites. In addition to decreased Bax phosphorylation at serine-184, which may be attributed to Akt kinase activity itself, wortmannin also enhanced Bax phosphorylation at threonine-167. Phosphorylation at this site has been previously suggested as a Bax-activating step and has been related to JNK and p38 pathways in staurosporine-treated hepatoma or chemotherapeutics-treated retinoblastoma cells. ${ }^{12,13,41}$ Whereas de-phosphorylation at serine-184 appeared to be independent of ROS, threonine-167 phosphorylation was largely prevented by $\alpha$-tocopherol as well as by NOX 4 siRNA, proving its clear dependency on ROS. Other relations between ROS and Bcl-2 proteins were so far mainly based on the expression level. Thus, $\mathrm{Bcl}-2$ and $\mathrm{Bcl}-\mathrm{xL}$ were downregulated, and Bax and Bak were upregulated in squamous cell carcinoma cells as a delayed result of enhanced intracellular ROS levels. ${ }^{42}$ The here identified link between ROS and Bax phosphorylation can, however, also explain the early effects of ROS in apoptosis control. Several different kinases might be involved in the threonine-167 phosphorylation of Bax. Thus, activation of ASK-1, JNK, p38, ERK1/2, PKC and CDKs by ROS had been reported. ${ }^{42,43}$ The Bax phosphorylation and activation assays, shown here, proved that Bax can be regulated independently by the two phosphorylation sites (Thr-167 and Ser-184), and only the threonine-167 phosphorylation depended on ROS.

Bax is a master regulator in mitochondrial proapoptotic pathways, and its particular role in TRAIL-induced apoptosis has been unraveled previously. ${ }^{5,6}$ Also, TRAIL/wortmannininduced apoptosis in melanoma cells was dependent on Bax, whereas the sister protein Bak played no role in this setting. Thus, Bak activity in melanoma cells had been reported as being controlled by distinct pathways related to VDAC2. ${ }^{44}$ $\mathrm{Bcl}-2$ represents the most critical antiapoptotic factor in melanoma. ${ }^{45,46}$ The model of mutual regulation of $\mathrm{Bcl}-2$ proteins by heterodimerization, in which $\mathrm{Bcl}-2$ acts as a particular antagonist of $\mathrm{Bax},{ }^{3}$ explains the strong antiapoptotic potential of $\mathrm{Bcl}-2$ seen here. Thus, ectopic overexpression of Bcl-2 completely abrogated wortmannin/TRAIL-induced apoptosis as well as the loss of $\Delta \psi \mathrm{m}$ and the activation of Bax (Bax-NT).

The synergistic enhancement of apoptosis by wortmannin and TRAIL is further explained by the proapoptotic Bcl-2 protein Bid, which is cleaved and activated by caspase-8. ${ }^{47}$ Thus, Bid activation by TRAIL in TRAIL-sensitive A-375 and TRAIL-resistant A-375-TS melanoma cells is shown here and was also previously reported by us. Furthermore, Bid knockdown prevented TRAIL-induced apoptosis in other combinations. ${ }^{30,48}$ Truncated Bid acts as an efficient antagonist, particularly of Bcl-2.5,49 Thus, the basal Bcl-2 levels in melanoma cells appeared sufficient to prevent apoptosis by wortmannin alone, despite the activation of Bax. This was also proven by siRNA knockdown of Bcl-2, which enabled apoptosis induction by wortmannin alone. On the other hand, efficient apoptosis by TRAIL alone was prevented by the inactivated Bax. The breakthrough in the combination treatment therefore resulted from Bax activation by wortmannin and simultaneous Bcl-2 inactivation by TRAIL-induced tBid (Figure 8d).

As concerns the downstream pathways in wortmannin/ TRAIL-induced apoptosis, significant release of apoptogenic mitochondrial factors (cytochrome $c$, Smac and AIF) was seen. The well-described pathways via cytochrome $c$ and Smac should induce caspase activation, ${ }^{3}$ which was however not seen here. Also, other, independent strategies for directly increasing ROS levels in melanoma cells have shown efficient apoptosis induction (DNA fragmentation), while caspases were completely shut off. ${ }^{15}$ This discrepancy may be explained by an inhibitory activity of ROS on caspases. Thus, ROS-mediated thiol oxidization may also result in the oxidization of the cysteine residues in the caspase catalytic sites, thus abrogating caspase activity and procaspase processing. ${ }^{50,51}$ The efficient apoptosis induction seen in the present study, however, proves the existence of strong pathways in melanoma cells, which drive DNA fragmentation independently of caspases. Under these conditions, cytochrome $c$ and Smac should lead to a dead end for apoptosis induction and other mitochondrial factors may take over, such as AIF and endonuclease G, which can trigger apoptosis independently of caspases. ${ }^{52,53}$

The present data suggest that melanoma apoptosis resistance is based on several levels, including high $\mathrm{Bcl}-2$ as reported previously ${ }^{45,46}$ as well as Bax inactivated by phosphorylation/de-phosphorylation. A third level was described recently, which is based on high XIAP expression, which prevents caspase activation and may be overcome by release of Smac. ${ }^{30,54}$ The inhibition by XIAP, however, was

Figure 8 NOX4 is essential for wortmannin-induced ROS production. (a) Apoptosis (\% of sub-G1 cells) and cytotoxicity (\% LDH release) in response to $24 \mathrm{~h}$ treatment with TRAIL $(20 \mathrm{ng} / \mathrm{ml})$ and/or wortmannin $(4 \mu \mathrm{M})$ was monitored in A-375 and Mel-HO after siRNA-mediated knockdown of NOX4. The respective mock control (Si-Ctrl) is shown for comparison. Mean values and SDs of two independent experiments, each with triplicates, are shown, and statistical significance is indicated $\left({ }^{*} P<0.005\right)$ when comparing NOX4 and mock-transfected cells after TRAIL/wortmannin treatment. Knockdown of NOX4 (70 kDa), as determined by western blotting, is shown in insets; equal protein loading ( $30 \mu \mathrm{g}$ per lane) was proven by GAPDH. (b) ROS levels were determined by $\mathrm{H}_{2} \mathrm{DCFDA}$ staining and flow cytometry in A-375 and Mel-HO after transfection with siRNA for NOX4 (Si-NOX4) and control siRNA (Si-Ctrl). Treatments with $20 \mathrm{ng} / \mathrm{ml}$ TRAIL $+/-4 \mu \mathrm{M}$ wortmannin were for $2 \mathrm{~h}$. Treated cells (open graphs) are compared to DMSO controls (gray). Two independent experiments (triplicates) revealed comparable results. (c) Flow cytometry signals for Bax phosphorylation (Ser-184, Thr-167) and Bax activation (Bax-NT) were compared in A-375, A-375-TS and Mel-HO cells transfected with NOX4 siRNA or control siRNA (Si-Ctrl). Treatments with TRAIL (20 ng/ml) + / wortmannin $(4 \mu \mathrm{M})$ were for $2 \mathrm{~h}$. Treated cells (open graphs) are shown in overlays with DMSO controls (gray). Two complete and independent experiments with triplicates revealed comparable results. (d) The suggested pathways induced by wortmannin/TRAIL are explaned within the text 
of no role in the present setting, as circumvented by a ROS-dependent and caspase-independent pathway.

The death ligand TRAIL has been suggested as a promising antitumor strategy, ${ }^{17,18}$ although inducible resistance was seen in different tumor models, also including melanoma. 22,55 Inducible resistance may also be the cause for the limited efficacy seen so far in clinical trials. ${ }^{19,20}$ Providing some hope, several strategies have been published in recent times that show efficient sensitization for TRAIL-induced apoptosis. ${ }^{30,48,54,56,57}$ The sensitization of melanoma cells is explained here by the activation of Bax, which results from changes at the phosphorylation level in dependence of Akt, NOX4 and ROS. This new pathway may be of significance for other proapoptotic strategies applied in melanoma and other cancers.

\section{Materials and Methods}

Cell culture. Human melanoma cell lines enclosed TRAIL-sensitive (A-375, Mel-HO) and TRAIL-resistant cells (Mel-2a and MeWo). ${ }^{58}$ Sublines with induced TRAIL resistance (Mel-HO-TS, A-375-TS) were derived from a selection with $100 \mathrm{ng} / \mathrm{ml}$ TRAIL. ${ }^{22}$ Other A-375 subclones had been stably transfected with a pIRES-Bcl-2 plasmid for Bcl-2 overexpression (A-375-Bcl-2) or with the pIRES empty plasmid (A-375-pIRES), as described previously. ${ }^{59}$ Parental HCT-116 colon carcinoma cells were derived from ATCC (Maryland, MD, USA). The HCT-116 Bax knockout, Bak knockdown and Bax/Bak double knockdown cells were kindly provided by B Vogelstein (John Hopkins Cancer Center, Baltimore, MD, USA) and had been described previously. ${ }^{6}$

Cells were cultivated at $37^{\circ} \mathrm{C}, 5 \% \mathrm{CO}_{2}$ in DMEM $(4.5 \mathrm{~g} / \mathrm{l}$ glucose; Gibco, Invitrogen, Karlsruhe, Germany), and supplemented with $10 \%$ FCS and antibiotics (Biochrom, Berlin, Germany). TRAIL-selected cells were continuously kept with $5 \mathrm{ng} / \mathrm{ml}$ TRAIL until $24 \mathrm{~h}$ before treatment. Cells were plated in 6-, 24- or 96-well plates with $2 \times 10^{5}, 5 \times 10^{4}$ and $5 \times 10^{3}$ cells, respectively, and treatment was started after $24 \mathrm{~h}$. For induction of apoptosis, TRAIL (Alexis, Gruenberg, Germany, ALX-201-073-C020, $20 \mathrm{ng} / \mathrm{ml})$, the PI3K inhibitor wortmannin $(4-8 \mu \mathrm{M}$, Santa Cruz Biotech., Santa Cruz, CA, USA) and the allosteric Akt inhibitor MK-2206 ((8-(4-(1-aminocyclobutyl)phenyl)-9-phenyl-(1,2,4)triazolo(3,4-f)(1,6)naphthyridin-3 (2H)-one; 0.5-8 $\mu \mathrm{M}$; Selleckchem, Munich, Germany) were used. Generally, in all our experiments both drugs were given together and for the same time. For caspase inhibition, cells were preincubated for $1 \mathrm{~h}$ with $10 \mu \mathrm{M}$ of the pancaspase inhibitor Q-VD-OPh (MP Biomedicals, Solon, OH, USA).

Cell proliferation, apoptosis and cytotoxicity. For continuous monitoring of cell growth, the xCELLigence system (Roche Diagnostics, Penzberg, Germany) was applied, and the relative cell indices were determined, which correspond to attached cell numbers. For quantification of apoptosis, cell cycle analyses were performed. ${ }^{60}$ In brief, treated cells (usually $24 \mathrm{~h}$ ) were harvested by trypsinization and stained for $1 \mathrm{~h}$ with propidium iodide (Sigma-Aldrich, Taufkirchen, Germany; $200 \mathrm{mg} / \mathrm{ml}$ ). Sub-G1 fractions corresponding to cells with fragmented DNA were quantified by flow cytometry (FACS Calibur, BD Biosciences, Bedford, MA, USA; 10000 cells gated, FL3H). Cytotoxicity was determined in parallel by measuring LDH activity in cell culture supernatants, applying a cytotoxicity detection assay (Roche Diagnostics).

Determination of $\Delta \psi \mathrm{m}$ and of ROS levels. $\Delta \psi \mathrm{m}$ was determined with the fluorescent dye TMRM $^{+}$(tetramethylrhodamine methyl ester perchlorate; Sigma-Aldrich; $1 \mathrm{mM}$ ). Cells were treated for $1-8 \mathrm{~h}$, harvested by trypsinization and stained with TMRM ${ }^{+}$for $15 \mathrm{~min}$ at $37^{\circ} \mathrm{C}$. Then, cells were measured in PBS by flow cytometry in a FACS Calibur ( $10^{4}$ gated cells, FL2H).

For determination of intracellular ROS, cells were treated for $1-8 \mathrm{~h}$. After trypsinization, cells were stained for 30 min with the fluorescent dye $\mathrm{H}_{2} \mathrm{DCFDA}$ (20,70-dichlorodihydrofluoresceindiacetate; Molecular Probes, Invitrogen, Eugene, OR, USA; $15 \mathrm{mM}$ ), and measured in PBS by flow cytometry in a FACS Calibur $\left(10^{4}\right.$ gated cells, FL1H). For ROS scavenging, cells were pretreated for $1 \mathrm{~h}$ with $200 \mu \mathrm{M} \alpha$-tocopherol (Fluka, Steinheim, Germany). As positive control, cells were treated with $\mathrm{H}_{2} \mathrm{O}_{2}(200 \mathrm{mM} ; 1 \mathrm{~h})$.

siRNA transfection. Transient cell transfection was performed in six-well plates at $24 \mathrm{~h}$ after seeding ( $70 \%$ confluence), and Wortmannin/TRAIL treatment followed after another $24 \mathrm{~h}$. Amounts of $20 \mathrm{pmol}$ siRNA and $4 \mu \mathrm{l}$ TurboFect (Fermentas, St. Leon-Rot, Germany) were used per well. The siRNAs for Bcl-2 (sc-61899), Bax (sc-29212), NOX4 (sc-41586) and the scrambled control (sc-37007) were derived from Santa Cruz Biotechnology.

Expression analyses. For western blotting, total protein extracts were obtained by cell lysis in $150 \mathrm{mM} \mathrm{NaCl}, 1 \mathrm{mM}$ EDTA, $2 \mathrm{mM}$ PMSF, $1 \mathrm{mM}$ leupeptin, $1 \mathrm{mM}$ pepstatin, $0.5 \%$ SDS, $0.5 \% \mathrm{NP}-40$ and $10 \mathrm{mM}$ Tris-HCl, pH 7.5. Cytosolic and mitochondrial cell fractions were separated by a kit of PromoKine (Heidelberg, Germany). Western blotting on nitrocellulose membranes was performed as described previously. ${ }^{61}$

Primary antibodies from Cell Signaling (Danvers, MA, USA): cleaved caspase-3 (3664, rabbit, 1:5000), caspase-3 (9662, rabbit, $1: 1000)$, caspase-8 (9746, mouse, $1: 1000)$, caspase-9 (9505, rabbit, $1: 1000)$, Bad (9292, rabbit, $1: 1000)$. Primary antibodies from Santa Cruz Biotech.: Mcl-1 (sc-12756, mouse, 1:200), Bcl-2 (sc-783, rabbit; 1:200), Bax (sc-493, rabbit, 1:200), Bid (sc-2002, rabbit, $1: 1000)$, NOX4 (sc-30141, rabbit, 1:1000), AIF (sc-9416, goat, 1:1000), Smac (sc-56230, mouse, $1: 1000$ ), GAPDH (sc-3233, mouse, $1: 1000)$, Puma (sc-374223, rabbit, 1:1000), VDAC 1,2,3 (sc-98708, rabbit, 1:1000). Further antibodies: cytochrome c (BD Biosciences, 529536, mouse, \#556433, 1: 1000), Noxa (ProSci, Poway, CA, USA; rabbit, 1:500), Secondary antibodies: peroxidase-labeled goat anti-rabbit, goat anti-mouse and rabbit anti-goat (Dako, Hamburg, Germany; 1: 5000).

Assays for Bax phosphorylation and activation. For analysis of Bax phosphorylation, assays were established for flow cytometry analysis of $\mathrm{pBax}$ (Ser-184) and pBax(Thr-167). Cells $\left(10^{5}\right)$ were harvested by trypsinization and fixed for $30 \mathrm{~min}$ with $4 \%$ paraformaldehyde in PBS. Cells were then incubated for $1 \mathrm{~h}$ at $4{ }^{\circ} \mathrm{C}$ with the respective antibodies in PBS/1\% FCS, which also contained $0.1 \%$ saponine for cell permeabilization. The following antibodies were used: phospho-Bax (Thr-167) (A0773, Assay Biotech, Sunnyvale, CA, USA, 1:300) and phospho-Bax (Ser-184) (A8297, Assay Biotech, 1:50); an antibody for total Bax (sc-493, rabbit, 1:300) was applied as control. Cells were subsequently incubated for $1 \mathrm{~h}$ at $4{ }^{\circ} \mathrm{C}$ in the dark with the secondary antibody: goat anti-rabbit $\lg \mathrm{G}(\mathrm{H}+\mathrm{L})$ FITC (Jackson Immuno Research, West Grove, PA, USA). After washing and re-suspension in PBS/ $1 \%$ FCS, cells were immediately measured by flow cytometry.

For the analysis of Bax conformational changes related to its activation, a primary antibody specific for the Bax N-terminal domain was applied in flow cytometry (Bax-NT, rabbit, Upstate, Lake Placid, NY, USA, \#06-499). According to the protocol described above, $10^{5}$ cells were harvested by trypsinization, fixed with $4 \%$ paraformaldehyde and incubated for $1 \mathrm{~h}$ at $4{ }^{\circ} \mathrm{C}$ with the Bax-NT antibody $(1: 100)$ in PBS $/ 1 \% \mathrm{FCS}+0.1 \%$ saponine. After incubation with the secondary antibody (goat anti-rabbit IgG $(\mathrm{H}+\mathrm{L})-\mathrm{FITC}$; Jackson Immuno Research), washing and re-suspension in PBS $/ 1 \%$ FCS, cells were measured by flow cytometry.

Statistical analyses. Assays consisted of triplicates, and at least two independent experiments were performed. Mean values and SDs were calculated by enclosing all individual values of the independent experiments (at least six values). Statistical significance was proven by Student's $t$-test (normal distribution) or Wilcoxon test (non-normal distribution of data), and $P$-values of $<0.05$ were considered statistically significant.

\section{Conflict of Interest}

The authors declare no conflict of interest.

Acknowledgements. The study has been supported by the German Cancer Aid (Deutsche Krebshilfe, Melanomverbund, 10-8008, TP7).

1. Krammer PH, Arnold R, Lavrik IN. Life and death in peripheral T cells. Nat Rev Immunol 2007; 7: 532-542.

2. Norberg $E$, Orrenius $S$, Zhivotovsky B. Mitochondrial regulation of cell death: processing of apoptosis-inducing factor (AIF). Biochem Biophys Res Co 2010; 396: 95-100.

3. Tait SWG, Green DR. Mitochondria and cell death: outer membrane permeabilization and beyond. Nat Rev Mol Cell Bio 2010; 11: 621-632.

4. Fischer U, Janicke RU, Schulze-Osthoff K. Many cuts to ruin: a comprehensive update of caspase substrates. Cell Death Differ 2003; 10: 76-100.

5. Chipuk JE, Moldoveanu T, Llambi F, Parsons MJ, Green DR. The BCL-2 family reunion. Mol Cell 2010; 37: 299-310. 
6. Gillissen B, Wendt J, Richter A, Richter A, Muer A, Overkamp T et al. Endogenous Bak inhibitors Mcl-1 and Bcl-xL: differential impact on TRAlL resistance in Bax-deficient carcinoma. J.Cell Biol 2010; 188: 851-862.

7. Westphal D, Dewson G, Czabotar PE, Kluck RM. Molecular biology of Bax and Bak activation and action. B B A-Mol Cell Res 2011; 1813: 521-531.

8. Youle RJ, Strasser A. The BCL-2 protein family: opposing activities that mediate cell death Nat Rev Mol Cell Bio 2008; 9: 47-59.

9. Walensky LD, Gavathiotis E. BAX unleashed: the biochemical transformation of an inactive cytosolic monomer into a toxic mitochondrial pore. Trends Biochem Sci2011; 36: 642-652.

10. Renault TT, Manon S. Bax: Addressed to kill. Biochimie 2011; 93: 1379-1391.

11. Xin MG, Deng XM. Protein phosphatase $2 A$ enhances the proapoptotic function of Bax through dephosphorylation. J Bio Chem 2006; 281: 18859-18867.

12. Kim BJ, Ryu SW, Song BJ. JNK- and p38 kinase-mediated phosphorylation of Bax leads to its activation and mitochondrial translocation and to apoptosis of human hepatoma HepG2 cells. J Bio Chem 2006; 281: 21256-21265.

13. Shen ZJ, Esnault S, Schinzel A, Borner C, Malter JS. The peptidyl-prolyl isomerase Pin facilitates cytokine-induced survival of eosinophils by suppressing Bax activation. Nat Immunol 2009; 10: 257-265.

14. Orrenius S. Reactive oxygen species in mitochondria-mediated cell death. Drug Metab Rev 2007; 39: 443-455

15. Franke JC, Plotz M, Prokop A, Geilen CC, Schmalz HG, Eberle J. New caspaseindependent but ROS-dependent apoptosis pathways are targeted in melanoma cells by an iron-containing cytosine analogue. Biochem. Pharmacol 2010; 79: 575-586.

16. Morgan MJ, Liu ZG. Reactive oxygen species in TNF alpha-induced signaling and cell death. Mol Cells 2010; 30: 1-12.

17. Ashkenazi A. Targeting death and decoy receptors of the tumour-necrosis factor superfamily. Nat Rev Cancer 2002; 2: 420-430.

18. Walczak H, Miller RE, Ariail K, Gliniak B, Griffith TS, Kubin M et al. Tumoricidal activity of tumor necrosis factor related apoptosis-inducing ligand in vivo. Nat Med 1999; 5: 157-163.

19. Herbst RS, Eckhardt SG, Kurzrock R, Ebbinghaus S, O'Dwyer PJ, Gordon MS et al. Phase I dose-escalation study of recombinant human Apo2L/TRAIL, a dual proapoptotic recepto agonist, in patients with advanced cancer. J.Clin. Oncol 2010; 28: 2839-2846.

20. Soria JC, Mark Z, Zatloukal P, Szima B, Albert I, Juhasz E et al. Randomized Phase II Study of dulanermin in combination with paclitaxel, carboplatin, and bevacizumab in Advanced Non-Small-Cell Lung Cancer. J Clin Oncol 2011; 29: 4442-4451.

21. Zhang XD, Wu JJ, Gillespie S, Borrow J, Hersey P. Human melanoma cells selected fo resistance to apoptosis by prolonged exposure to tumor necrosis factor-related apoptosisinducing ligand are more vulnerable to necrotic cell death induced by cisplatin. Clin Cancer Res 2006; 12: 1355-1364.

22. Kurbanov BM, Fecker LF, Geilen CC, Sterry W, Eberle J. Resistance of melanoma cells to TRAIL does not result from upregulation of antiapoptotic proteins by NF-kappaB but is related to downregulation of initiator caspases and DR4. Oncogene 2007; 26: 3364-3377.

23. Flaherty KT, Infante JR, Daud A, Gonzalez R, Kefford RF, Sosman J et al. Combined BRAF and MEK Inhibition in Melanoma with BRAF V600 Mutations. New Engl J Med 2012 367: 1694-1703.

24. Dillon RL, Muller WJ. Distinct biological roles for the Akt family in mammary tumo progression. Cancer Res 2010; 70: 4260-4264.

25. Aziz SA, Jilaveanu LB, Zito C, Camp RL, Rimm DL, Conrad P et al. Vertical targeting of the phosphatidylinositol-3 kinase pathway as a strategy for treating melanoma. Clin Cancer Res 2010; 16: 6029-6039.

26. Sinnberg T, Lasithiotakis K, Niessner H, Schittek B, Flaherty KT, Kulms D et al. Inhibition of PI3K-AKT-mTOR signaling sensitizes melanoma cells to cisplatin and temozolomide. J.Invest Dermatol 2009; 129: 1500-1515.

27. Lemke LE, Paine-Murrieta GD, Taylor CW, Powis G. Wortmannin inhibits the growth of mammary tumors despite the existence of a novel wortmannin-insensitive phosphatidylinositol-3-kinase. Cancer Chemoth and Pharm 1999; 44: 491-497.

28. Upton JP, Valentijn AJ, Zhang L, Gilmore AP. The N-terminal conformation of Bax regulates cell commitment to apoptosis. Cell Death Differ 2007; 14: 932-942.

29. Berger A, Quast SA, Plotz M, Kammermeier A, Eberle J. Sensitization of melanoma cells for TRAIL-induced apoptosis by BMS-345541 correlates with altered phosphorylation and activation of Bax. Cell Death Dis 2013; 4: e477.

30. Quast SA, Berger A, Buttstadt N, Friebel K, Schonherr R, Eberle J. General sensitization of melanoma cells for TRAIL-induced apoptosis by the potassium channel inhibitor TRAM-34 depends on release of SMAC. PLOS One 2012; 7: e39290.

31. Ayral-Kaloustian S, Gu JX, Lucas J, Cinque M, Gaydos C, Zask A et al. Hybrid inhibitors of phosphatidylinositol 3-kinase (PI3K) and the mammalian target of rapamycin (mTOR): design, synthesis, and superior antitumor activity of novel wortmannin-rapamycin conjugates. J Med Chem 2010; 53: 452-459.

32. Chen XF, Thakkar H, Tyan F, Gim S, Robinson H, Lee $\mathrm{C}$ et al. Constitutively active Akt is an important regulator of TRAIL sensitivity in prostate cancer. Oncogene 2001; 20: 6073-6083.

33. Kandasamy K, Srivastava RK. Role of the phosphatidylinositol 3 '-kinase/PTEN/Akt kinase pathway in tumor necrosis factor-related apoptosis-inducing ligand-induced apoptosis in non-small cell lung cancer cells. Cancer Res 2002; 62: 4929-4937.

34. Hersey P, Zhang XD. Overcoming resistance of cancer cells to apoptosis. J Cell Physiol 2003; 196: 9-18.

35. Bozulic L, Hemmings BA. PIKKing on PKB: regulation of PKB activity by phosphorylation. Curr Opin Cell Biol 2009; 21: 256-261.
36. Shi HB, Kong XJ, Ribas A, Lo RS. Combinatorial treatments that overcome PDGFR betadriven resistance of melanoma cells to B-V600E-RAF inhibition. Cancer Res 2011; 71: 5067-5074.

37. Sangai T, Akcakanat A, Chen HQ, Tarco E, Wu Y, Do KA et al. Biomarkers of response to Akt inhibitor MK-2206 in breast cancer. Clin Cancer Res 2012; 18: 5816-5828.

38. Mochizuki T, Furuta S, Mitsushita J, Shang W, Ito M, Yokoo Y et al. Inhibition of NADPH oxidase 4 activates apoptosis via the AKT/apoptosis signal-regulating kinase 1 pathway in pancreatic cancer PANC-1 cells. Oncogene 2006; 25: 3699-3707.

39. Naughton R, Quiney C, Turner SD, Cotter TG. Bcr-Abl-mediated redox regulation of the PI3K/AKT pathway. Leukemia 2009; 23: 1432-1440.

40. Bedard K, Krause KH. The NOX family of ROS-generating NADPH oxidases: Physiology and pathophysiology. Physiol Rev 2007; 87: 245-313.

41. Min HB, Ghatnekar GS, Ghatnekar AV, You XH, Bu M, Guo XY et al. 2-Methoxyestradiol induced bax phosphorylation and apoptosis in human retinoblastoma cells via p38 MAPK activation. Mol Carcinogen 2012; 51: 576-585.

42. Li DC, Ueta E, Kimura T, Yamamoto T, Osaki T. Reactive oxygen species (ROS) control the expression of $\mathrm{Bcl}-2$ family proteins by regulating their phosphorylation and ubiquitination. Cancer Sci 2004; 95: 644-650.

43. Verbon EH, Post JA, Boonstra J. The influence of reactive oxygen species on cell cycle progression in mammalian cells. Gene 2012; 511: 1-6.

44. Plötz M, Gillissen B, Hossini AM, Daniel PT, Eberle J. Disruption of the VDAC2-Bak interaction by $\mathrm{Bcl}-\mathrm{xS}$ mediates efficient induction of apoptosis in melanoma cells. Cell Death Differ 2012; 19: 1928-1938.

45. Jansen B, Wacheck V, Heere-Ress E, Schlagbauer-Wadl H, Hoeller C, Lucas T et al. Chemosensitization of malignant melanoma by BCL2 antisense therapy. Lancet 2000; 356: 1728-1733.

46. Eberle J, Kurbanov BM, Hossini AM, Trefter U, Fecker LF. Overcoming apoptosis deficiency of melanoma - Hope for new therapeutic approaches. Drug Resist Update 2007; 10: 218-234.

47. Kaufmann T, Strasser A, Jost PJ. Fas death receptor signalling: roles of Bid and XIAP. Cell Death Differ 2012; 19: 42-50.

48. Berger A, Quast SA, Plotz M, Hein M, Kunz M, Langer P et al. Sensitization of melanoma cells for death ligand-induced apoptosis by an indirubin derivative-enhancement of both extrinsic and intrinsic apoptosis pathways. Biochem Pharmacol 2010; 81: 71-81.

49. Song G, Chen GG, Hu T. Lai PBS. Bid stands at the crossroad of stress-response pathways. Curr Cancer Drug Targets 2010; 10: 584-592.

50. Hampton MB, Winterbourn CC, Stamenkovic I. Mechanisms of caspase inactivation by hydrogen peroxide. Free Radic Bio Med 1998; 25: S89.

51. Borutaite V, Brown GC. Caspases are reversibly inactivated by hydrogen peroxide. FEBS Lett 2001; 500: 114-118.

52. Tait SWG, Green DR. Caspase-independent cell death: leaving the set without the final cut. Oncogene 2008; 27: 6452-6461.

53. D'Anneo A, Carlisi D, Lauricella M, Emanuele S, Di Fiore R, Vento R et al. Parthenolide induces caspase-independent and AIF-mediated cell death in human osteosarcoma and melanoma cells. J Cell Physiol 2012; 228: 952-967.

54. Hornle M, Peters N, Thayaparasingham B, Vorsmann H, Kashkar H, Kulms D. Caspase-3 cleaves XIAP in a positive feedback loop to sensitize melanoma cells to TRAIL-induced apoptosis. Oncogene 2010; 30: 575-587.

55. Li Y, Wang H, Wang Z, Makhija S, Buchsbaum D, LoBuglio A et al. Inducible resistance of tumor cells to tumor necrosis factor-related apoptosis-inducing ligand receptor 2-mediated apoptosis by generation of a blockade at the death domain function. Cancer Res 2006; 66: $8520-8528$.

56. Ivanov VN, Partridge MA, Johnson GE, Huang SX, Zhou H, Hei TK. Resveratrol sensitizes melanomas to TRAIL through modulation of antiapoptotic gene expression. Exp Cell Res 2008; 314: 1163-1176.

57. Jiang CC, Chen LH, Gillespie S, Kiejda KA, Mhaidat N, Wang YF et al. Tunicamycin sensitizes human melanoma cells to tumor necrosis factor-related apoptosis-inducing ligand-induced apoptosis by up-regulation of TRAIL-R2 via the unfolded protein response. Cancer Res 2007; 67: 5880-5888.

58. Kurbanov BM, Geilen CC, Fecker LF, Orfanos CE, Eberle J. Efficient TRAll-R1/DR4mediated apoptosis in melanoma cells by tumor necrosis factor-related apoptosis-inducing ligand (TRAIL). J Invest Dermatol 2005; 125: 1010-1019.

59. Raisova M, Hossini A, Riebeling C, Wieder T, Daniel P, Eberle J et al. Apoptosis resistance in human melanoma cells. J Invest Dermatol 2001; 117: 168.

60. Riccardi $\mathrm{C}$, Nicoletti I. Analysis of apoptosis by propidium iodide staining and flow cytometry. Nat Protoc 2006; 1: 1458-1461.

61. Eberle J, Fecker LF, Hossini AM, Wieder T, Daniel PT, Orfanos CE et al. CD95/Fas signaling in human melanoma cells: conditional expression of CD95L/FasL overcomes the intrinsic apoptosis resistance of malignant melanoma and inhibits growth and progression of human melanoma xenotransplants. Oncogene 2003; 22: 9131-9141.

Cell Death and Disease is an open-access journal published by Nature Publishing Group. This work is licensed under a Creative Commons Attribution-NonCommercialNoDerivs 3.0 Unported License. To view a copy of this license, visit http://creativecommons.org/licenses/by-nc-nd/3.0/ 